\title{
The co-chaperone Fkbp5 shapes the acute stress response in the paraventricular nucleus of the hypothalamus of male mice
}

\author{
Alexander S. Häusl ${ }^{1} \cdot$ Lea M. Brix ${ }^{1,2} \cdot$ Jakob Hartmann $\mathbb{1}^{3} \cdot$ Max L. Pöhlmann ${ }^{1} \cdot$ Juan-Pablo Lopez ${ }^{4}$. \\ Danusa Menegaz ${ }^{5}$. Elena Brivio $\mathbb{D}^{2,4}$. Clara Engelhardt ${ }^{1}$. Simone Roeh ${ }^{6}$. Thomas Bajaj ${ }^{7} \cdot$ Lisa Rudolph $^{4}$.

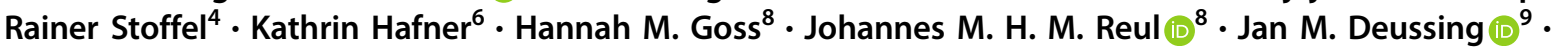 \\ Matthias $\operatorname{Eder}^{5} \cdot$ Kerry J. Ressler $\mathbb{D}^{3} \cdot$ Nils C. Gassen $\mathbb{D}^{6,7} \cdot$ Alon Chen $^{4,10} \cdot$ Mathias V. Schmidt $\mathbb{D}^{1}$
}

Received: 21 November 2019 / Revised: 19 January 2021 / Accepted: 2 February 2021 / Published online: 1 March 2021

(c) The Author(s) 2021. This article is published with open access

\begin{abstract}
Disturbed activation or regulation of the stress response through the hypothalamic-pituitary-adrenal (HPA) axis is a fundamental component of multiple stress-related diseases, including psychiatric, metabolic, and immune disorders. The FK506 binding protein 51 (FKBP5) is a negative regulator of the glucocorticoid receptor (GR), the main driver of HPA axis regulation, and FKBP5 polymorphisms have been repeatedly linked to stress-related disorders in humans. However, the specific role of $F k b p 5$ in the paraventricular nucleus of the hypothalamus (PVN) in shaping HPA axis (re)activity remains to be elucidated. We here demonstrate that the deletion of $F k b p 5$ in Sim $1^{+}$neurons dampens the acute stress response and increases GR sensitivity. In contrast, $F k b p 5$ overexpression in the PVN results in a chronic HPA axis over-activation, and a PVN-specific rescue of $F k b p 5$ expression in full Fkbp5 KO mice normalizes the HPA axis phenotype. Single-cell RNA sequencing revealed the cell-type-specific expression pattern of $F k b p 5$ in the PVN and showed that $F k b p 5$ expression is specifically upregulated in $\mathrm{Crh}^{+}$neurons after stress. Finally, $\mathrm{Crh}$-specific $\mathrm{Fkbp} 5$ overexpression alters $\mathrm{Crh}$ neuron activity, but only partially recapitulates the PVN-specific Fkbp5 overexpression phenotype. Together, the data establish the central and cell-type-specific importance of Fkbp5 in the PVN in shaping HPA axis regulation and the acute stress response.
\end{abstract}

These authors contributed equally: Alexander S. Häusl, Lea M. Brix

Supplementary information The online version contains supplementary material available at https://doi.org/10.1038/s41380021-01044-x.

Mathias V. Schmidt

mschmidt@psych.mpg.de

1 Research Group Neurobiology of Stress Resilience, Max Planck Institute of Psychiatry, Munich, Germany

2 International Max Planck Research School for Translational Psychiatry (IMPRS-TP), Munich, Germany

3 Department of Psychiatry, Harvard Medical School, McLean Hospital, Belmont, MA, USA

4 Department of Stress Neurobiology and Neurogenetics, Max Planck Institute of Psychiatry, Munich, Germany

5 Electrophysiology Core Unit, Max Planck Institute of Psychiatry, Munich, Germany

\section{Introduction}

Life is full of challenges and appropriate coping with such events implies proper activation and termination of the stress response. The hypothalamic-pituitary-adrenal (HPA) axis is the central orchestrator of the stress response and its end product glucocorticoids (cortisol in humans, corticosterone (CORT) in rodents) mediates the adaptation to acute

6 Department of Translational Research in Psychiatry, Max Planck Institute of Psychiatry, Munich, Germany

7 Department of Psychiatry and Psychotherapy, Bonn Clinical Center, University of Bonn, Bonn, Germany

8 Neuro-Epigenetics Research Group, Bristol Medical School, University of Bristol, Bristol, United Kingdom

9 Research Group Molecular Neurogenetics, Max Planck Institute of Psychiatry, Munich, Germany

10 Department of Neurobiology, Weizmann Institute of Science, Rehovot, Israel 
and chronic stressors in peripheral tissues as well as in the brain [1]. A hallmark of HPA axis regulation is the negative feedback on the secretion of stress hormones to terminate the stress response which is controlled by glucocorticoids via the glucocorticoid receptor (GR).

A critical regulator of GR and therefore key to a successful termination of the stress response is FK506 binding protein 51 (FKBP5), which is encoded by the FKBP5 gene [2]. FKBP5 is an Hsp90-associated co-chaperone that restricts GR function by reducing ligand binding, delaying nuclear translocation, and decreasing GR-dependent transcriptional activity [3, 4]. Hence, higher levels of FKBP5 mRNA are associated with higher levels of circulating cortisol and reduced negative feedback inhibition of the stress response [5-9]. Consequently, GR-induced FKBP5 levels reflect the environmental stress condition, and as such, $F K B P 5$ expression has been used as a stress-responsive gene marker [10]. Importantly, FKBP5 polymorphisms have been consistently associated with stress-related psychiatric disorders such as major depression and PTSD [11-13], where a demethylation-mediated increase in FKBP5 expression was identified as causal in risk-allele carriers [14].

Despite the central importance of FKBP5 in stress system biology and stress-related disorders, detailed functional and mechanistic studies are still largely missing. Only a few human post-mortem studies focus on central tissue in order to dissect FKBP5 mechanisms [15, 16], while the majority of studies use peripheral blood mononuclear cells as a correlate of FKBP5 brain activity [17]. Most of the animal data were obtained from wild-type (WT) or conventional Fkbp5 knockout mice, thereby lacking cell-type-specific insights of Fkbp5 function [8, 18]. To tackle this paucity of information, we here investigate the specific role of Fkbp5 in the paraventricular nucleus of the hypothalamus (PVN) the key brain region orchestrating the stress response [19]. Interestingly, previous data in rats suggested a potentially decisive role of Fkbp5 expression in the PVN to drive HPA axis hyperactivity achieved by a selective breeding approach [20]. Using site-specific manipulations of Fkbp5, single-cell RNA expression profiling, and functional downstream pathway analyzes, our data unravel a key role of PVN Fkbp5 in shaping the body's stress system (re) activity, with important implications for its contribution to stress-related disorders.

\section{Material and methods}

\section{Animals and animal housing}

All experiments were performed in accordance with the European Communities' Council Directive 2010/63/EU. The protocols were approved by the committee for the care and use of laboratory animals of the Government of Upper Bavaria, Germany. The mouse lines Fkbp5 $5^{\text {lox/lox }}$, $F k b p 5^{\mathrm{PVN}-1-}, F k b p 5^{\mathrm{Frt} / \mathrm{Frt}}$, and CRH-ires-CRE/Ai9 were generated in house. Experiments were performed on male mice aged between 3 and 5 months unless stated otherwise in the results section. During the experimental time, animals were kept singly housed in individually ventilated cages (IVC; $30 \mathrm{~cm} \times 16 \mathrm{~cm} \times 16 \mathrm{~cm} ; 501 \mathrm{~cm}^{2}$ ), serviced by a central airflow system (Tecniplast, IVC Green LineGM500). Animals were maintained on a 12:12 h light/dark cycle, with constant temperature $\left(23 \pm 2{ }^{\circ} \mathrm{C}\right)$ and humidity of $55 \%$ during all times. Experimental animals received ad libitum access to water and a standard research diet (Altromin 1318, Altromin GmbH, Germany) and IVCs had sufficient bedding and nesting material as well as a wooden tunnel for environmental enrichment. Animals were allocated to experimental groups in a semi-randomized fashion and data analysis was performed blinded to the group allocation.

\section{Generation of Fkbp5 mice}

Conditional Fkbp5 knockout mice are derived from embryonic stem cell clone EPD0741_3_H03 which was targeted by the knockout mouse project (KOMP). Frozen sperm obtained from the KOMP repository at UC Davis was used to generate knockout mice $\left(F k b p 5^{\text {tmla(KOMP)Wtsi }}\right)$ by in vitro fertilization. These mice designated as $F k b p 5^{\mathrm{Frt} / \mathrm{Frt}}$ are capable to re-express functional Fkbp5 upon Flp recombinase-mediated excision of an frt-flanked reporter-selection cassette integrated into the Fkbp5 gene. Mice with a floxed Fkbp5 gene designated as $F k b p 5^{\text {lox/lox }}\left(F k b p 5^{\text {tmlc(KOMP)Wtsi }}\right)$ were obtained by breeding $F k b p 5^{\mathrm{Frt} / \mathrm{Frt}}$ mice to Deleter-Flpe mice [21]. Finally, mice lacking $F k b p 5$ in PVN neurons $\left(F k b p 5^{\mathrm{PVN}-/-}\right)$ were obtained by breeding $F k b p 5^{\text {lox/lox }}$ mice to Sim1-Cre mice [22]. The CRH-ires-CRE/Ai9 mouse line was generated previously [23]. Genotyping details are available upon request.

\section{Viral overexpression and rescue of Fkbp5}

For overexpression and rescue experiments, stereotactic injections were performed as described previously [24]. In brief, mice aged between 10 and 12 weeks were anesthetized with isoflurane, and $0.2 \mu \mathrm{l}$ of the below-mentioned viruses (titers: $1.6 \times 10^{12-13}$ genomic particles $/ \mathrm{ml}$ ) were bilaterally injected in the PVN at $0.05 \mu \mathrm{l} / \mathrm{min}$ by glass capillaries with tip resistance of $2-4 \mathrm{M} \Omega$ in a stereotactic apparatus. The following coordinates were used: $-0.45 \mathrm{~mm}$ anterior to bregma, $0.3 \mathrm{~mm}$ lateral from midline, and 4.8 $\mathrm{mm}$ below the surface of the skull, targeting the PVN. After surgery, mice were treated for 3 days with Metacam via i.p. injections and were allowed to recover for 3-4 weeks before 
the start of the testing. Successful overexpression or reinstatement of $F k b p 5$ was verified by ISH and RNAscope. For in vivo experiments, we used adeno-associated bicistronic AAV1/2 vectors. In the overexpression experiments, the vector contained a CAG-HA-tagged-FKBP51-WPREBGH-polyA expression cassette (containing the coding sequence of human Fkbp51 NCBI CCDS ID CCDS4808.1). The same vector constructs without expression of Fkbp5 (CAG-Null/Empty-WPRE-BGH-polyA) was used as a control. For the Crh specific overexpression of Fkbp5, we used a viral vector containing an AAV1/2-Cre-dept-HAFKBP51 (pAAV-Cre-dependent-CAG-HA-human wildtype FKBP51 WPRE-BGH-polyA) and a control virus containing AAV1/2-Cre-dept-GFP (pAAV-Cre-dependent-CAGGFP-WPRGE-BGH-polyA). Virus production, amplification, and purification were performed by GeneDetect. For the rescue experiment, a viral vector containing a flippase expressing cassette (AAV2-eSYN-eGFP-T2A-FLPo, Vector Biolabs; VB1093) was used to induce endogenous Fkbp5 expression in $F k b p 5^{\mathrm{FRT} / \mathrm{FRT}}$ mice. Control animals were injected with a control virus (AAV2-eSYN-eGFP; Vector Biolabs; VB1107).

\section{Acute stress paradigm}

For acute stress exposure, the restraint stress paradigm was used, as it was shown to be a reliable and robust stressor in rodents [25]. One to $2 \mathrm{~h}$ after lights on each animal was placed in a restrainer $(50 \mathrm{ml}$ falcon tube with holes at the bottom and the lid to provide enough oxygen and space for tail movement) for $15 \mathrm{~min}$ in their individual home cage. After $15 \mathrm{~min}$, animals were removed from the tube and the first blood sample was collected by tail cut. Until the following tail cuts at 30,60, and 90 min after stress onset, the animals remained in their home cage to recover. Basal CORT levels (morning CORT) were collected one week prior to the acute stress paradigm at 8 a.m.

\section{Combined Dex/CRH test}

To investigate the HPA axis function we performed a combined Dex/CRH test as described previously [8]. On an experimental day, mice were injected with a low dose of dexamethasone $(0.05 \mathrm{mg} / \mathrm{kg}$, Dex-Ratiopharm, 7633932) via i.p injections at 9 a.m. in the morning. At this dose Dex does not cross the blood-brain barrier and acts predominantly in the periphery [26] Here, the most important site of action in relation to HPA axis function, especially when combined with a challenge with the neuropeptide $\mathrm{CRH}$, is the pituitary. Thus, $6 \mathrm{~h}$ after Dex injection, a blood sample was collected via tail cut (after Dex value), followed by an injection of CRH $(0.15 \mathrm{mg} / \mathrm{kg}$, CRH Ferrin Amp). Thirty-minute after CRH injection, another blood sample was obtained (after CRH value). All samples from the acute stress experiments and the Dex/CRH test were collected in $1.5 \mathrm{ml}$ EDTA-coated microcentrifuge tubes (Sarstedt, Germany). All blood samples were kept on ice and were centrifuged for $15 \mathrm{~min}$ at $8000 \mathrm{rpm}$ and $4{ }^{\circ} \mathrm{C}$. Plasma was transferred to new, labeled microcentrifuge tubes and stored at $-20{ }^{\circ} \mathrm{C}$ until further processing.

\section{Sampling procedure}

On the day of sacrifice, animals were deeply anesthetized with isoflurane and sacrificed by decapitation. Trunk blood was collected in labeled $1.5 \mathrm{ml}$ EDTA-coated microcentrifuge tubes (Sarstedt, Germany) and kept on ice until centrifugation. After centrifugation $\left(4{ }^{\circ} \mathrm{C}, 8000 \mathrm{rpm}\right.$ for 1 min) the plasma was removed and transferred to new, labeled tubes and stored at $-20^{\circ} \mathrm{C}$ until hormone quantification. For mRNA analysis, brains were removed, snapfrozen in isopentane at $-40{ }^{\circ} \mathrm{C}$, and stored at $-80{ }^{\circ} \mathrm{C}$ for ISH. For protein analysis, brains were removed and placed inside a brain matrix with the hypothalamus facing upwards (spacing $1 \mathrm{~mm}$, World Precision Instruments, Berlin, Germany). Starting from the middle of the chiasma opticum, a $1 \mathrm{~mm}$ thick brain slice was removed. The PVN was further isolated by cutting the slice on both sides of the PVN along the fornices (parallel to the 3rd ventricle) as a landmark and a horizontal cut between the reuniens and the thalamic nucleus. Finally, the slice containing the third ventricle was bisected, and the distal part discarded. The remaining part (containing the PVN) was immediately shocked frozen and stored at $-80{ }^{\circ} \mathrm{C}$ until protein analysis [27]. The adrenals and thymus glands were dissected from fat and weighed.

\section{Hormone assessment}

CORT and ACTH concentrations were determined by radioimmunoassay using a corticosterone double-antibody ${ }^{125}$ I RIA kit (sensitivity: $12.5 \mathrm{ng} / \mathrm{ml}$, MP Biomedicals Inc.) and adrenocorticotropic double-antibody hormone ${ }^{125}$ I RIA kit (sensitivity: $10 \mathrm{pg} / \mathrm{ml}$, MP Biomedicals Inc.) and were used following the manufacturers' instructions. Radioactivity of the pellet was measured with a gamma counter (Packard Cobra II Auto Gamma; Perkin-Elmer). Fifteenminute post-stress analysis of ACTH concentrations was analyzed by using ACTH ELISA (IBL international GmBH, RE53081) and the ELISA was performed as recommended by the manufacturer. Final CORT and ACTH levels were derived from the standard curve.

\section{In situ hybridization (ISH)}

ISH was used to analyze mRNA expression of the major stress markers, $\mathrm{Fkbp5,Gr}, \mathrm{Crh}$, and Avp. Therefore, frozen 
brains were sectioned at $-20{ }^{\circ} \mathrm{C}$ in a cryostat microtome at $20 \mu \mathrm{m}$, thaw mounted on Super Frost Plus slides, dried, and stored at $-80{ }^{\circ} \mathrm{C}$. The ISH using ${ }^{35} \mathrm{~S}$ UTP labeled ribonucleotide probes was performed as described previously [28, 29]. All primer details are available upon request. Briefly, sections were fixed in $4 \%$ paraformaldehyde and acetylated in $0.25 \%$ acetic anhydride in $0.1 \mathrm{M}$ triethanolamine/HCl. Subsequently, brain sections were dehydrated in increasing concentrations of ethanol. The antisense cRNA probes were transcribed from a linearized plasmid. Tissue sections were saturated with $100 \mu \mathrm{l}$ of hybridization buffer containing approximately $1.5 \times 10^{6} \mathrm{cpm}{ }^{35} \mathrm{~S}$ labeled riboprobe. Brain sections were coverslipped and incubated overnight at $55^{\circ} \mathrm{C}$. On the next day, the sections were rinsed in $2 \times \mathrm{SSC}$ (standard saline citrate), treated with RNAse A (20 mg/l). After several washing steps with SSC solutions at room temperature, the sections were washed in $0.1 \times \mathrm{SSC}$ for $1 \mathrm{~h}$ at $65^{\circ} \mathrm{C}$ and dehydrated through increasing concentrations of ethanol. Finally, the slides were air-dried and exposed to Kodak Biomax MR films (Eastman Kodak Co., Rochester, NY) and developed. Autoradiographs were digitized, and expression was determined by optical densitometry utilizing the freely available NIH ImageJ software. The mean of four measurements of two different brain slices was calculated for each animal. The data were analyzed blindly, always subtracting the background signal of a nearby structure not expressing the gene of interest from the measurements. For Fkbp5, exemplary slides were dipped in Kodak NTB2 emulsion (Eastman Kodak Co., Rochester, NY) and exposed at $4{ }^{\circ} \mathrm{C}$ for representative pictures; exposure time was adjusted to average expression level. Slides were developed and examined with a light microscope with darkfield condensers to show mRNA expression.

\section{RNAscope analysis and cell counting}

For the RNAscope experiments, $\mathrm{C} 57 \mathrm{Bl} / 6$ male mice were obtained from The Jackson Laboratory (Bar Harbor, ME, USA). All procedures conformed to National Institutes of Health guidelines and were approved by McLean Hospital Institutional Animal Care and Use Committee. Mice were housed in a temperature-controlled colony in the animal facilities of McLean Hospital in Belmont, MA, USA. All mice were group-housed and maintained on a 12:12 h light/ dark cycle (lights on at 7 a.m.). Food and water were available ad libitum unless specified otherwise. Mice were 12 weeks at the time of tissue collection. Animals were allowed to acclimate to the room for 1 week before the beginning of the experiment. During the experiment, mice were either left undisturbed (ctrl) or subjected to $14 \mathrm{~h}$ (overnight) of food deprivation prior to sacrifice. During the stress procedure, animals were kept in their home cages and had free access to tap water. All mice were sacrificed by decapitation in the morning (08:00 to 08:30 a.m.) following quick anesthesia by isoflurane. Brains were removed, snapfrozen in isopentane at $-40^{\circ} \mathrm{C}$, and stored at $-80^{\circ} \mathrm{C}$. Frozen brains were sectioned in the coronal plane at $-20^{\circ} \mathrm{C}$ in a cryostat microtome at $18 \mu \mathrm{m}$, mounted on Super Frost Plus slides, and stored at $-80^{\circ} \mathrm{C}$. The RNA Scope Fluorescent Multiplex Reagent kit (cat. no. 320850, Advanced Cell Diagnostics, Newark, CA, USA) was used for mRNA staining. Probes used for staining were; mm-Avp-C3, mmCrh-C3, mm-Fkbp5-C2, mm-Oxt-C3, mm-Sst-C3, and mmTrh-C3. The staining procedure was performed according to the manufacturer's specifications. Briefly, sections were fixed in $4 \%$ paraformaldehyde for $15 \mathrm{~min}$ at $4{ }^{\circ} \mathrm{C}$. Subsequently, brain sections were dehydrated in increasing concentrations of ethanol. Next, tissue sections were incubated with protease IV for $30 \mathrm{~min}$ at room temperature. Probes (probe diluent (cat. no. 300041 used instead of C1-probe), Fkbp5-C2, and one of the above $\mathrm{C} 3$-probes) were hybridized for $2 \mathrm{~h}$ at $40{ }^{\circ} \mathrm{C}$ followed by four hybridization steps of the amplification reagents 1-4. Next, sections were counterstained with DAPI, cover-slipped, and stored at $4{ }^{\circ} \mathrm{C}$ until image acquisition. Images of the PVN (left and right side) were acquired by an experimenter blinded to the condition of the animals. Sixteen-bit images of each section were acquired on a Leica SP8 confocal microscope using a $40 \times$ objective ( $n=3$ animals per marker and condition). For every individual marker, all images were acquired using identical settings for laser power, detector gain, and amplifier offset. Images of both sides were acquired as a $\mathrm{z}$ stack of 3 steps of $1.0 \mu \mathrm{m}$ each. Fkbp 5 mRNA expression and co-expression were analyzed using ImageJ with the experimenter blinded to the condition of the animals. Fkbp5 mRNA was counted manually and each cell containing 1 mRNA dot was counted as positive.

\section{Single-cell sequencing. Tissue dissociation}

Single-cell sequencing was performed on PVN tissue dissected from male C57B1/6 mice aged between 8 and 12 weeks. Therefore, mice were anesthetized lethally using isoflurane and perfused with cold PBS. Brains were quickly dissected, transferred to ice-cold oxygenated artificial cerebral spinal fluid (aCSF), and kept in the same solution during dissection. Sectioning was performed using a $0.5 \mathrm{~mm}$ stainless steel adult mouse brain matrice (Kent Scientific) and a Personna double edge prep razor blade. A slide (approximately $-0.58 \mathrm{~mm}$ Bregma to $-1.22 \mathrm{~mm}$ Bregma) was obtained from each brain and the extended PVN was manually dissected under the microscope. The PVN from five different mice was pooled and dissociated using the Papain dissociation system (Worthington) following the manufacturer's instructions. All solutions were 
oxygenated with a mixture of $5 \% \mathrm{CO}_{2}$ in $\mathrm{O}_{2}$. After this, the cell suspension was filtered with a $30 \mu \mathrm{m}$ filter (Partec) and kept in cold and oxygenated aCSF.

\section{Cell capture, library preparation, and high- throughput sequencing}

Cell suspensions of PVN with $\sim 1,000,000$ cells/ $\mu \mathrm{L}$ were used. Cells were loaded onto two lanes of a 10X Genomics Chromium chip per factory recommendations. Reverse transcription and library preparation was performed using the 10X genomics single-cell v2.0 kit following the $10 \mathrm{X}$ genomics protocol. The library molar concentration and fragment length were quantified by qPCR using KAPA Library Quant (Kapa Biosystems) and Bioanalyzer (Agilent high sensitivity DNA kit), respectively. The library was sequenced on a single lane of an Illumina HiSeq4000 system generating 100 bp paired-end reads at a depth of $\sim 340$ million reads per sample.

\section{Quality control and identification of cell clusters}

Pre-processing of the data was done using the $10 \mathrm{X}$ genomics cell ranger software version 2.1.1 in default mode. The 10X genomics supplied reference data for the mm10 assembly and corresponding gene annotation was used for alignment and quantification. All further analysis was performed using SCANPY version 1.3.7 [30]. A total of 5.113 cells were included after filtering gene counts $(<750$ and $>6.000$ ), UMI counts $(>25.000)$, and the fraction of mitochondrial counts $(>0.2)$. Combat [31] was used to remove chromium channels as batch effects from normalized data. The 4.000 most variable genes were subsequently used as input for Louvain cluster detection. Cell types were determined using a combination of marker genes identified from the literature and gene ontology for cell types using the web-based tool: mousebrain.org (http://mousebrain.org/ genesearch.html).

\section{Western blot analysis}

Protein extracts were obtained by lysing cells in RIPA buffer (150 mM NaCl, 1\% IGEPAL CA-630, 0.5\% Sodium deoxycholate, $0.1 \%$ SDS $50 \mathrm{mM}$ Tris (pH8.0)) freshly supplemented with protease inhibitor (Merck Millipore, Darmstadt, Germany), benzonase (Merck Millipore), 5 mM DTT (Sigma Aldrich, Munich, Germany), and phosphatase inhibitor cocktail (Roche, Penzberg, Germany). Proteins were separated by SDS-PAGE and electro-transferred onto nitrocellulose membranes. Blots were placed in Tris-buffered saline, supplemented with $0.05 \%$ Tween (Sigma Aldrich) and 5\% non-fat milk for $1 \mathrm{~h}$ at room temperature, and then incubated with primary antibody (diluted in TBS/ $0.05 \%$ Tween) overnight at $4{ }^{\circ} \mathrm{C}$. The following primary antibodies were used: Actin (1:5000, Santa Cruz Biotechnologies, sc-1616), GR (1:1000, Cell Signaling Technology, \#3660), p-GR Ser211 (1:500, Sigma, SAB4503820), p-GR Ser226 (1:1000, Sigma, SAB4503874), p-GR 203 (1:500, Sigma, SAB4504585), FKBP51 (1:1000, Bethyl, A301-430A).

Subsequently, blots were washed and probed with the respective horseradish peroxidase or fluorophoreconjugated secondary antibody for $1 \mathrm{~h}$ at room temperature. The immuno-reactive bands were visualized either using ECL detection reagent (Millipore, Billerica, MA, USA) or directly by excitation of the respective fluorophore. Determination of the band intensities was performed with BioRad, ChemiDoc MP. For quantification of phosphorylated GR, the intensity of phosphor-GR was always referred to as the signal intensity of the corresponding total GR.

\section{Chromatin preparation for chromatin immunoprecipitation (ChIP) analysis}

The GR ChIP was performed as previously described [32]. We added $1 \mathrm{mM}$ AEBSF or $0.1 \mathrm{mM}$ PMSF, $5 \mathrm{mM} \mathrm{Na}{ }^{+}$ Butyrate (NaBut), and PhosSTOP phosphatase inhibitor cocktail tablets (1 per $10 \mathrm{ml}$; Roche, Burgess Hill, UK) to all solutions unless otherwise stated. Briefly, hypothalamus tissues from four mice were cross-linked for $10 \mathrm{~min}$ in $1 \%$ formaldehyde in PBS. Crosslinking was terminated by adding glycine $(5 \mathrm{~min}$, final concentration $200 \mu \mathrm{M})$ and centrifuged $\left(5 \mathrm{~min}, 6000 \mathrm{~g}, 4^{\circ} \mathrm{C}\right.$ ). Pellets were washed three times with ice-cold PBS. Next, the pellets were resuspended in ice-cold Lysis Buffer $[50 \mathrm{mM}$ Tris- $\mathrm{HCl} \mathrm{pH}$ 8, $150 \mathrm{mM} \mathrm{NaCl}, 5 \mathrm{mM}$ EDTA pH 8.0, 0.5\% v/v Igepal, $0.5 \%$ Na-deoxycholate, $1 \%$ SDS, $5 \mathrm{mM}$ NaBut, $2 \mathrm{mM}$ AEBSF, $1 \mathrm{mM}$ Na3VO4, complete ultra EDTA-free protease inhibitor tablets and PhosSTOP phosphatase inhibitor cocktail tablet (both 1 per $10 \mathrm{ml}$, Roche, Burgess Hill, UK)] and rotated for $15 \mathrm{~min}$ at $4{ }^{\circ} \mathrm{C}$. Samples were aliquoted, sonicated (high power; $2 \times 10$ cycles; $30 \mathrm{~s}$ ON, $60 \mathrm{~s}$ OFF) using a water-cooled $\left(4{ }^{\circ} \mathrm{C}\right)$ Bioruptor Pico (Diagenode, Liège, Belgium) and centrifuged (10 $\left.\mathrm{min}, 20,000 \mathrm{~g}, 4^{\circ} \mathrm{C}\right)$. Supernatants (containing the sheared chromatin) were recombined and re-aliquoted into fresh tubes for subsequent ChIP analysis and for assessment of Input DNA (i.e., the starting material). Chromatin was sonicated to a length of $\sim 500$ base pairs.

\section{For ChIP analysis}

Aliquots of chromatin were diluted ten-times in ice-cold Dilution Buffer [50 mM Tris- $\mathrm{HCl} \mathrm{pH} 8.0,150 \mathrm{mM} \mathrm{NaCl}, 5$ mM EDTA pH 8.0, $1 \%$ v/v Triton, $0.1 \%$ Na-deoxycholate 5 $\mathrm{mM}$ NaBut, $1 \mathrm{mM}$ AEBSF, complete ultra EDTA-free protease inhibitor tablets and PhosSTOP phosphatase inhibitor 
cocktail tablet (both 1 per $10 \mathrm{ml}$, Roche)]. $10 \mu \mathrm{l}$ of GR antibody (ProteinTech, USA) was added to each sample, and tubes were rotated overnight at $4{ }^{\circ} \mathrm{C}$. Protein A-coated Dynabeads $^{\circledR}$ (Life Technologies) were washed once in icecold $0.5 \%$ BSA/PBS before blocking overnight at $4{ }^{\circ} \mathrm{C}$. Preblocked beads were washed once in ice-cold Dilution buffer, re-suspended in the antibody:chromatin mix, and allowed to incubate for $3 \mathrm{~h}$ at $4{ }^{\circ} \mathrm{C}$ to allow binding of beads to antibody:chromatin complexes. After $3 \mathrm{~h}$, the samples were placed in a magnetic stand to allow the beads (with the Bound fraction bound) to separate from the liquid "Unbound" fraction. Beads carrying the Bound chromatin were washed three times with ice-cold RIPA buffer [10 mM Tris-HCl pH 7.5, 1 mM EDTA pH 7.5, 0.1\% SDS, $0.5 \mathrm{mM}$ EGTA, $1 \%$ Triton, $0.1 \%$ Na-Deoxycholate, $140 \mathrm{mM}$ $\mathrm{NaCl}+$ inhibitors] and washed twice with ice-cold TrisEDTA buffer. Bound DNA was eluted in two steps at room temperature; first with $200 \mu \mathrm{l}$ Elution buffer $1(10 \mathrm{mM}$ Tris$\mathrm{HCl} \mathrm{pH} \mathrm{7.4,} 50 \mathrm{mM} \mathrm{NaCl}, 1.5 \%$ SDS) and second with $100 \mu$ Elution buffer $2(10 \mathrm{mM}$ Tris-HCl $\mathrm{pH} 7.4,50 \mathrm{mM}$ $\mathrm{NaCl}, 0.5 \%$ SDS). Crosslinks were reversed by the addition of $\mathrm{NaCl}$ (final concentration $200 \mathrm{mM}$ ) and overnight incubation at $65^{\circ} \mathrm{C}$. The next day, samples were incubated first with RNase A $\left(60 \mu \mathrm{g} / \mathrm{ml}, 37^{\circ} \mathrm{C}, 1 \mathrm{~h}\right)$, followed by incubation with proteinase $\mathrm{K}\left(250 \mu \mathrm{g} / \mathrm{ml}, 37^{\circ} \mathrm{C}, 3.5 \mathrm{~h}\right)$. DNA was purified using a QIAquick PCR purification kit (Qiagen) as per the manufacturer's instructions. Input samples were incubated overnight at $65^{\circ} \mathrm{C}$ with $200 \mathrm{mM} \mathrm{NaCl}$ to reverse crosslinks, incubated with RNase A and proteinase K (overnight), and DNA was purified using a Qiagen PCR purification kit. All samples (bounds and inputs) were diluted to a standardized concentration with nuclease-free water and analyzed by qPCR as described below using primers/probes (forward: 5'-TGTCAATGGACAAGTCATAAGAAACC; reverse: 5'-GAATCTCACATCCAATTATATCAACAGAT; probe: 5'-TTCCATTTTCGGGCTCGTTGACGTC). The binding of GR was expressed as a percentage of input DNA, i.e., \% Input, which is a measure of the enrichment of steroid receptor bound to specific genomic sequences.

\section{qPCR analysis}

Mastermix for qPCR was prepared to contain $900 \mathrm{nM}$ forward and reverse primers, $200 \mathrm{nM}$ probe, $1 \mathrm{X}$ TaqMan fast mastermix (Life Technologies, Paisley, UK), and nucleasefree water. Primers and dual-labeled probes with 6-FAM as the fluorescent dye and TAMRA are the quencher were designed using Primer Express software (Version 3.0.1, Life Technologies). Standard curves were performed for each primer pair and the qPCR efficiency was calculated using the equation: $E=((10-1 /$ slope $)-1) \times 100$ (where $E$ is qPCR efficiency and the slope is the gradient of the standard curve). Only primer pairs with efficiencies greater than $90 \%$ were used. Quantitative PCR was performed using a StepOne Plus machine (Life Technologies, Paisley, UK). Taq enzymes were activated at $95^{\circ} \mathrm{C}$ for $20 \mathrm{~s}$, then 40 cycles of $95^{\circ} \mathrm{C}(1 \mathrm{~s})$ to $60^{\circ} \mathrm{C}(20 \mathrm{~s})$ were performed to amplify samples.

\section{Electrophysiology}

A separate cohort of CRH-ires-CRE/Ai9 mice (Fkbp5 ${ }^{\mathrm{CRH} O \mathrm{OE}}$ $n=4$, Control $n=4$ ) was used for electrophysiology experiments. Mice underwent surgery as described above. After 3-4 weeks of recovery, mice were anesthetized with isoflurane and decapitated. The brain was rapidly removed from the cranial cavity and, using a vibratome (HM650V, Thermo Scientific), $350 \mu \mathrm{m}$-thick coronal slices containing the PVN were cut in an ice-cold carbonated gas $(95 \%$ $\mathrm{O}_{2} / 5 \% \mathrm{CO}_{2}$ )-saturated solution consisting of (in $\mathrm{mM}$ ): 87 $\mathrm{NaCl}, 2.5 \mathrm{KCl}, 25 \mathrm{NaHCO}_{3}, 1.25 \mathrm{NaH}_{2} \mathrm{PO}_{4}, 0.5 \mathrm{CaCl}_{2}, 7$ $\mathrm{MgCl}_{2}, 10$ glucose, and 75 sucrose. Slices were incubated in carbonated physiological saline for $30 \mathrm{~min}$ at $34{ }^{\circ} \mathrm{C}$ and, afterward, for at least $30 \mathrm{~min}$ at room temperature $\left(23-25^{\circ} \mathrm{C}\right)$. The physiological saline contained (in $\mathrm{mM}$ ): $125 \mathrm{NaCl}, 2.5 \mathrm{KCl}, 25 \mathrm{NaHCO}_{3}, 1.25 \mathrm{NaH}_{2} \mathrm{PO}_{4}, 2 \mathrm{CaCl}_{2}, 1$ $\mathrm{MgCl}_{2}$, and 10 glucose. Using infrared video microscopy, somatic whole-cell voltage-clamp recordings from control and FKBP51-overexpressing PVN neurons (identified by fluorescence imaging; seal resistance $>1 \mathrm{G} \Omega$; holding potential $-70 \mathrm{mV}$, corrected for a liquid junction potential of $10 \mathrm{mV}$ ) were performed with an EPC 10 amplifier (HEKA) at room temperature in physiological saline (2-3 ml/min flow rate) containing picrotoxin $(100 \mu \mathrm{M})$ and TTX $(1 \mu \mathrm{M})$. Patch pipettes (3-4 M $\Omega$ open tip resistance) were filled with a solution consisting of (in $\mathrm{mM}$ ): 125 $\mathrm{CsCH}_{3} \mathrm{SO}_{3}, 8 \mathrm{NaCl}, 10$ HEPES, 0.5 EGTA, $4 \mathrm{Mg}$-ATP, 0.3 $\mathrm{Na}-\mathrm{GTP}$, and $20 \mathrm{Na}_{2}$-phosphocreatine (pH adjusted to 7.2 with $\mathrm{CsOH}$ ). Five minutes after a break-in to the cell, AMPA receptor-mediated miniature excitatory postsynaptic currents (mEPSCs) were recorded for $5 \mathrm{~min}$. Offline analysis of mEPSCs was conducted using the Mini Analysis Program (Synaptosoft). Recordings, where series resistance changed by more than $10 \%$, were excluded from the analysis.

\section{Statistical analysis}

The data presented are shown as means \pm SEM and sample sizes are indicated in the figure legends. All data were analyzed by the commercially available software SPSS 17.0 and GraphPad 8.0. When two groups were compared, the unpaired student's $t$-test was applied. If data were not normally distributed the non-parametric Mann-Whitney test (MW-test) was used. For four group comparisons, a twoway analysis of variance (ANOVA) was performed, 


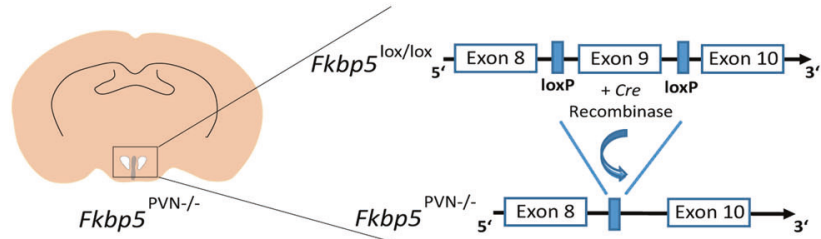

\section{है}

C Body physiology
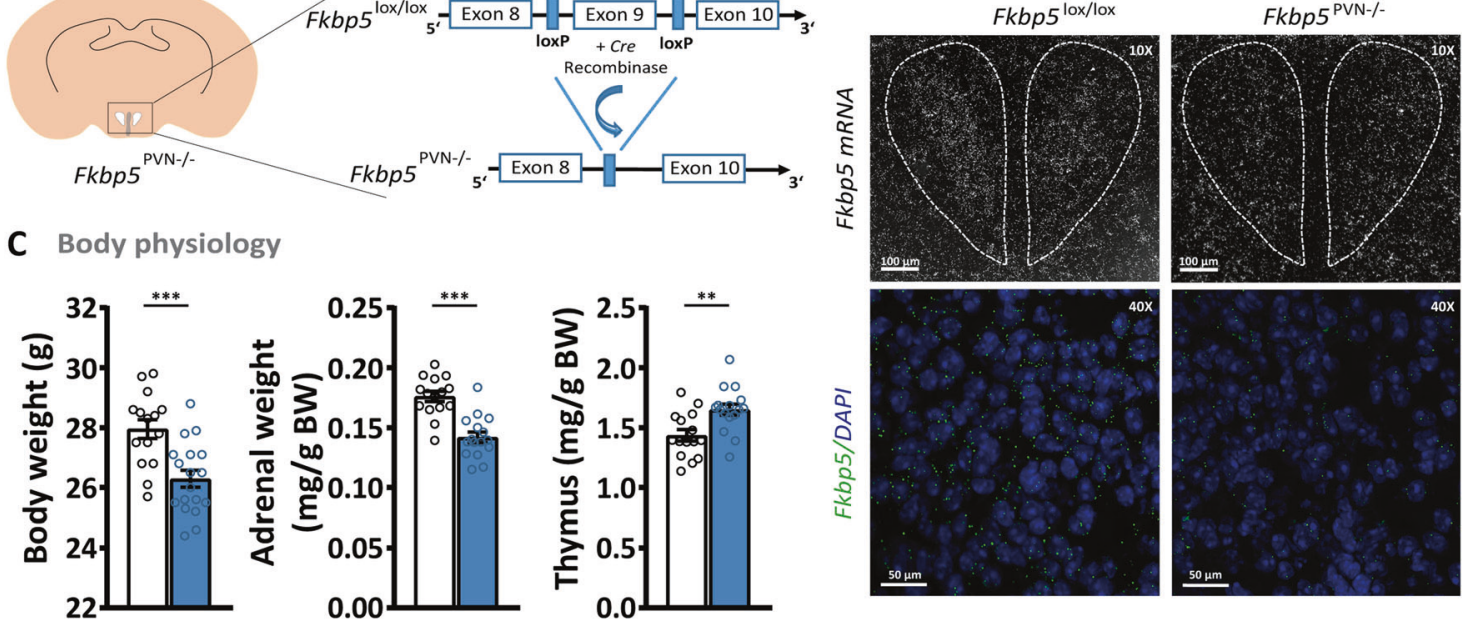

D Acute stress response
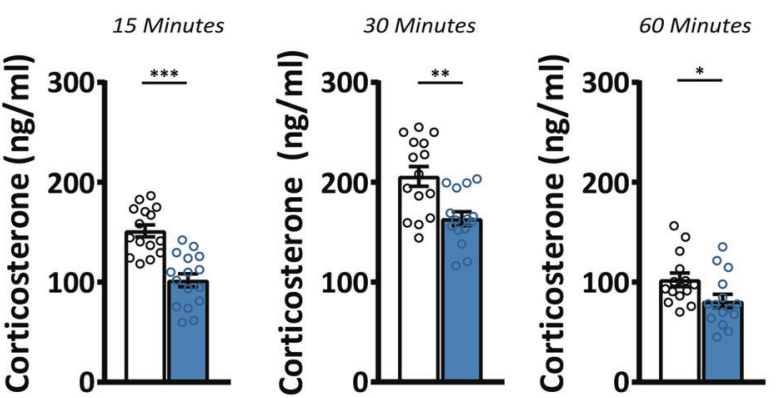

E Combined Dex/CRH Test

Fig. 1 Loss of Fkbp5 in the PVN alters HPA axis physiology. A Cre-LoxP based generation of the $F k b p 5^{\mathrm{PVN}-1-}$ mouse line. B Validation of Fkbp5 mRNA expression in the PVN via in situ hybridization (ISH) and RNAscope (for mRNA quantification see Supplementary Fig. 1A). C $F k b p 5^{\mathrm{PVN}-/-}$ mice $(n=16)$ presented reduced body weight, lowered adrenal weights, and increased thymus weights under non-stressed conditions compared to their WT littermates $(n=15)$. D Corticosterone levels were significantly reduced

followed by a posthoc test, as appropriate. $P$ values of less than 0.05 were considered statistically significant. The sample size was chosen such that with a type 1 error of 0.05 and a type 2 error of 0.2 the effect size should be at least 1.2 -fold of the pooled standard deviation. All data were tested for outliers using the Grubbs test.

\section{Results}

\section{Loss of Fkbp5 in the PVN alters HPA axis physiology}

To study the effects of Fkbp5 in the PVN, we first generated PVN-specific conditional Fkbp5 knockout mice $\left(F k b p 5^{\mathrm{PVN}-l-}\right)$ by crossing $F k b p 5^{\text {lox/lox }}$ mice (generated in-house; for details see methods) with the Sim1-Cre mouse line, which expresses $\mathrm{Cre}$ recombinase in $\mathrm{Sim} 1^{+}$ following a $15 \mathrm{~min}$ restraint stress until at least $60 \mathrm{~min}$ after stress onset. E A combined Dex/CRH test showed a significantly pronounced response to a low dose of dexamethasone as well as a dampened response to $\mathrm{CRH}$ injection. Data are received from mice between 16 and 20 weeks of age and are presented as mean \pm SEM. All data were analyzed with a student's $t$-test. $* p<0.05$, $* *<0.01$, and $* * * p<0.001$

neurons mostly concentrated within the PVN (Fig. 1A). The successful deletion of Fkbp5 in the PVN was assessed by mRNA and protein analysis (Fig. 1B and Supplementary Fig. 1). Under basal conditions, adult mice (16-20 weeks of age) lacking Fkbp5 in the PVN showed significantly lower body-, and adrenal weights and higher thymus weights compared to their WT littermates (Fig. 1C). Interestingly, Fkbp $5^{\mathrm{PVN}-1-}$ mice in young adolescence ( 8 weeks of age) showed no significant differences in body weight, adrenal, or thymus weights (Supplementary Fig. 2), indicating an agedependent phenotype of Fkbp5 in the HPA-axis' response.

As PVN Fkbp 5 mRNA levels are highly responsive to an acute stressor [10], we hypothesized that $F k b p 5^{\mathrm{PVN}-I-}$ mice have an altered stress response following an acute challenge. Under basal conditions during the circadian trough, 
no differences in corticosterone secretion were detected in young and adult mice (Supplementary Figs. 1 and 2). However, already after $15 \mathrm{~min}$ of restraint stress adult and young $F k b p 5^{\mathrm{PVN}-1-}$ mice displayed significantly reduced plasma corticosterone levels compared to the control group (Fig. 1D). The dampened stress response was persistent for $60 \mathrm{~min}$ in adult mice, while the effect has vanished in young mice already $30 \mathrm{~min}$ after stress onset (Fig. 1D and Supplementary Fig. 2). Levels of the adrenocorticotropic hormone $(\mathrm{ACTH})$ were not altered under basal or acute stressed conditions (Supplementary Fig. 1).

To further investigate the effect of Fkbp5 on GR sensitivity, we performed combined dexamethasone (Dex, a synthetic GC)—corticotropin-releasing hormone (CRH) test on adults $F k b p 5^{\mathrm{PVN}-1-}$ mice. The combined Dex/CRH test is a method to analyze HPA axis (dys)function in depressed individuals or animals, measuring the responsiveness of the body's stress response system through suppression (by Dex injection) and stimulation (by $\mathrm{CRH}$ injection) of the HPA axis [33]. The injection of a low dose of Dex $(0.05 \mathrm{mg} / \mathrm{kg})$ resulted in a reduction in blood corticosterone levels compared to the evening corticosterone levels in both groups. Interestingly, mice lacking Fkbp5 in the PVN showed 1.5fold lower levels of corticosterone compared to their WT littermates. Following CRH stimulation $(0.15 \mathrm{mg} / \mathrm{kg})$ $F k b p 5^{\mathrm{PVN}-1-}$ mice showed a significantly lower reaction to $\mathrm{CRH}$ than control mice (Fig. 1E). These data indicate that specific deletion of Fkbp5 in the PVN dampens HPA axis response and enhances GR sensitivity.

\section{Overexpression of Fkbp5 in the PVN induces a stress-like phenotype in C57BI/6 mice under basal conditions}

Chronic or acute stress upregulates Fkbp5 in distinct brain regions, such as the PVN [10]. Therefore, we were interested to explore whether selective overexpression of Fkbp5 in the PVN would be sufficient to affect body physiology and stress system regulation. To do so, we bilaterally injected $200 \mathrm{nl}$ of an adeno-associated virus (AAV) containing an Fkbp5 overexpression vector into the PVN of 10-12 weeks old C57B1/6 mice (Fkbp5 $5^{\mathrm{PVN} \mathrm{OE}}$, Fig. 2A, B). The AAV-mediated overexpression resulted in a (fourfold) increase in Fkbp5 mRNA and protein levels (Fkbp5) in the PVN (Supplementary Fig. 3).

Intriguingly, Fkbp5 overexpression altered the physiology of stress-responsive organs. $F k b p 5^{\mathrm{PVN}}$ OE animals showed a significantly reduced thymus weight and increased adrenal weights compared to their littermates (Fig. 2C), the hallmark of chronically stressed animals $[34,35]$. Furthermore, overexpression of Fkbp5 affected the circadian rhythm of corticosterone secretion, indicated by increased blood corticosterone levels in the morning as well as the evening (Fig. 2D). Consequently, ACTH levels of $F k b p 5^{\mathrm{PVN}} \mathrm{OE}$ animals were also increased under nonstressed conditions (Supplementary Fig. 3). Next, we analyzed distinguished stress markers under basal conditions in order to determine whether consequences of PVN-specific Fkbp5 overexpression are also detectable at the molecular level. Nrlc3 and Crh mRNA expression in the PVN were increased in $F k b p 5^{\mathrm{PVN} \text { OE }}$ animals under basal conditions; however, to a lesser extent than the increase of Fkbp5 mRNA due to viral overexpression. Avp mRNA levels were not altered (Supplementary Fig. 3). Together, these results are comparable to chronically stressed animals and demonstrate that local overexpression of Fkbp5 in the PVN is sufficient to mimic a stress-like phenotype without physically challenging the animals.

In accordance with the knock-out studies of the $F k b p 5^{\mathrm{PVN}-1-}$ animals, we investigated the endocrinology of $F k b p 5^{\mathrm{PVN} O E}$ animals after an acute challenge. As expected, we detected higher blood corticosterone levels in $F k b p 5^{\mathrm{PVN}}$ $\mathrm{OE}$ mice 15 and $30 \mathrm{~min}$ after stress onset compared to the stressed controls (Fig. 2E). However, we could not detect any difference in ACTH release after stress (Supplementary Fig. 3). No differences between both groups were observed 60 and $90 \mathrm{~min}$ after restraint stress (Fig. 2E and Supplementary Fig. 3). These data show that $F k b p 5^{\mathrm{PVN} O E}$ mice have a hyperactive HPA axis response and are more vulnerable to acute stress exposure.

To further assess GR sensitivity in Fkbp5 overexpressing animals, we again tested the response to a combined Dex/ CRH test. While control animals showed a decline $(<5 \mathrm{ng} /$ $\mathrm{ml}$ ) in blood corticosterone levels $6 \mathrm{~h}$ after Dex injection, $F k b p 5^{\mathrm{PVN} O E}$ mice showed almost no response to Dex treatment (Fig. 2F). Interestingly, the subsequent CRH injection resulted in a higher corticosterone release in Fkbp5 $5^{\mathrm{PVN} O E}$ mice compared to controls (Fig. 2F). These results suggest that excess levels of Fkbp5 in the PVN lead to a decreased GR sensitivity and thereby to an altered HPA axis response. Taken together, animals overexpressing Fkbp5 in the PVN show a hyperactive function of the HPA axis under basal and acute stress conditions, thereby mimicking the physiological hallmarks of chronic stress exposure and HPA axis hyperactivity, as observed in multiple stress-related diseases [36].

\section{Reinstatement of endogenous Fkbp5 in the PVN of global Fkbp5 knock-out animals normalizes the body's stress response}

Global loss of Fkbp5 results in a more sensitive GR and better-coping behavior of mice after stress [8, 17, 28, 34], and our results demonstrated that Fkbp5 in the PVN is necessary for an undisturbed stress system function. Thus, we were encouraged to test whether the reinstatement of 
A Experimental procedure

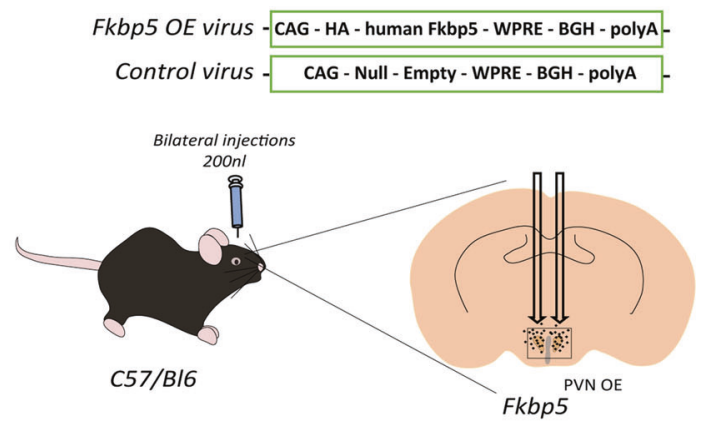

B Virus validation
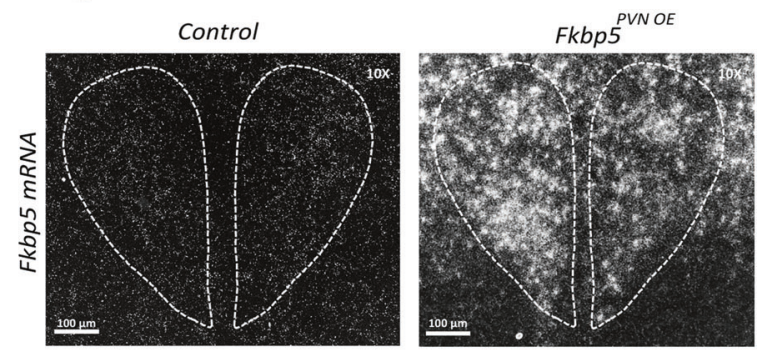

C Body physiology
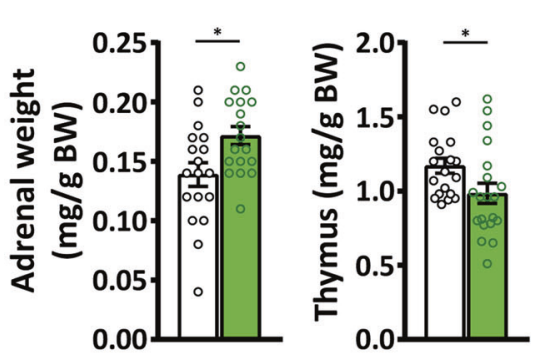

D Basal corticosterone level
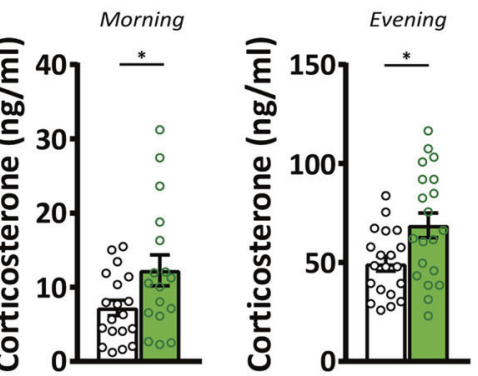

E Acute stress response
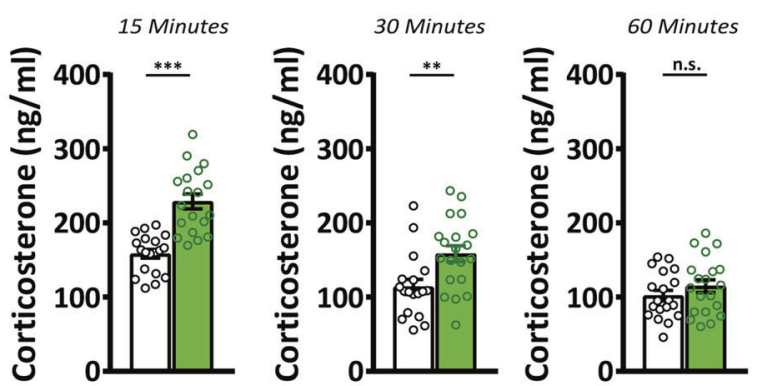

F Combined Dex/CRH Test

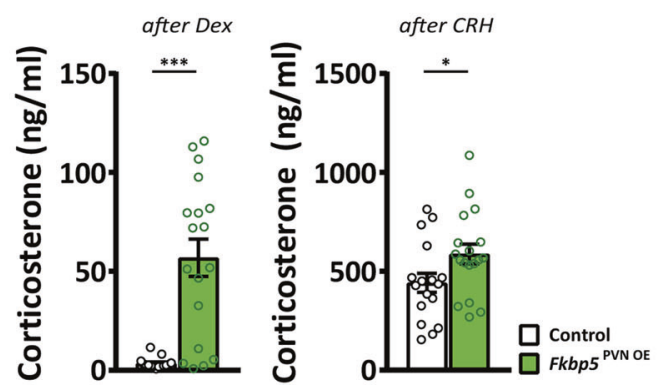

Fig. 2 The overexpression of Fkbp5 in $\mathrm{C} 57 \mathrm{Bl} / 6$ mice induces a stress-like phenotype under basal conditions. A Overexpression of Fkbp5 in the PVN was achieved by bilateral viral injections. B Validation of Fkbp5 mRNA overexpression in the PVN by ISH (see Supplementary Fig. 3A for mRNA quantification). C Fkbp5 $5^{\mathrm{PVN} \text { OE }}$ mice $(n=20)$ showed significantly increased adrenal weights and a reduced thymus weight under non-stressed conditions compared to the controls $(n=20)$. D Fkbp5 overexpression resulted in heightened corticosterone levels during the day. E Fifteen and $30 \mathrm{~min}$ after stress

native Fkbp5 expression only in the PVN is sufficient to push the HPA axis activity of global Fkbp5 knock-out animals to a wildtype level. Therefore, we injected an Flp recombinase expressing virus into 12-14 weeks old $F k b p 5^{\mathrm{Frt} / \mathrm{Frt}}$ mice. These mice carry an FRT flanked reporter selection (stop) cassette within the Fkbp5 locus, leading to a disruption of the Fkbp5 function. We compared $F k b p 5^{\mathrm{Fr} t / \mathrm{Frt}}$ mice to WT littermates and observed a similar HPA-axis phenotype to the well-established Fkbp5 full KO lines ([8] and Supplementary Fig. 4). An Flp removes the stop cassette from the Fkbp5 locus, resulting in endogenous Fkbp5 re-expression (Fig. 3A, B, Supplementary Fig. 5). In onset, $F k b p 5^{\mathrm{PVN} O E}$ mice displayed significantly higher corticosterone levels. F $F k b p 5^{\mathrm{PVN} O E}$ mice showed significantly elevated corticosterone $6 \mathrm{~h}$ after dexamethasone treatment. The following CRH injection further significantly increased the corticosterone release compared to controls. Data are presented as mean \pm SEM. All data were received from mice between 14 and 20 weeks of age and analyzed a with student's $t$-test. $* p<0.05, \quad * * p<0.01, \quad * * * p<0.001, \quad n . s$. not significant.

parallel to the two previous mouse models, we assessed body physiology, basal corticosterone levels, and the acute stress response. Interestingly, mice with re-instated $F k b p 5$ expression $\left(F k b p 5^{\mathrm{PVN} \text { Rescue }}\right)$ showed significantly higher adrenal weights as compared to their control littermates (Fig. 3C). Furthermore, we observed that the reinstatement of Fkbp5 in the PVN resulted in significantly increased blood CORT levels in the morning under basal conditions (Fig. 3D), with no effect on thymus weights, evening CORT, and ACTH levels (Supplementary Fig. 5). ISH analysis revealed significantly higher levels of $\mathrm{Crh}$ mRNA, but no changes in $N r 1 c 3$ and Avp mRNA expression in the 
A Experimental procedure

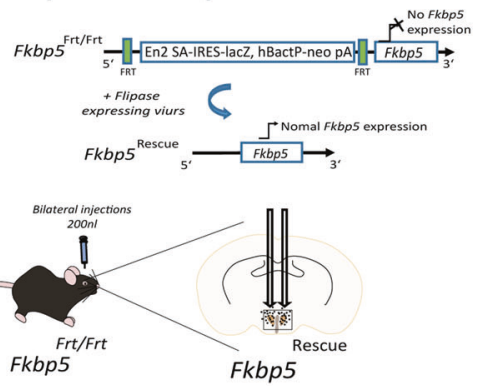

B Virus validation

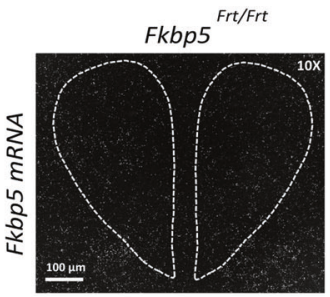

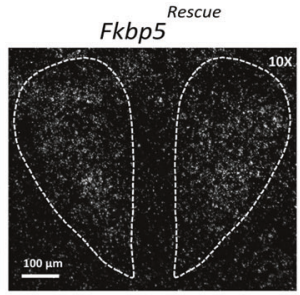

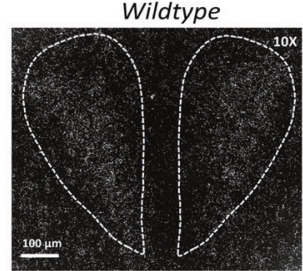

C Body physiology

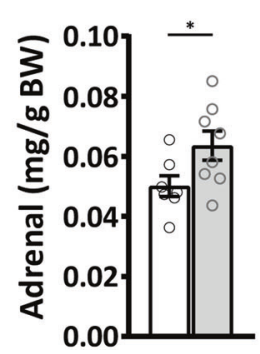

Fig. 3 The reinstatement of endogenous Fkbp5 in the PVN of global Fkbp5 knock-out animals. A Experimental procedure. B Validation of successful Fkbp5 rescue by ISH (see Supplementary Fig. 5A for mRNA quantification) and comparable WT Fkbp5 expression. C The reinstatement of $F k b p 5$ in the PVN resulted in increased adrenal weights and elevated morning corticosterone levels

PVN under basal conditions (Supplementary Fig. 5). Next, we monitored blood corticosterone levels after $15 \mathrm{~min}$ of restraint stress. Here, we observed significantly higher corticosterone levels 15 and $60 \mathrm{~min}$ after stress onset (Fig. 3E). No differences were detected in the combined Dex/CRH test (Supplementary Fig. 5), which suggests that a PVN-driven over-activation of the HPA axis might be necessary for desensitization of GRs in the PVN and the pituitary. These rescue experiments underline the importance of Fkbp5 in the acute stress response and demonstrate that Fkbp5 in the PVN is necessary and sufficient to regulate HPA axis (re)activity.

\section{Fkbp5 manipulation directly affects GR phosphorylation}

It is well known that ligand-binding induced phosphorylation of GR plays an important role in response to hormone signaling [37]. The main phosphorylation sites involved in

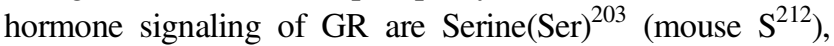
$\mathrm{Ser}^{211}$ (mouse $\mathrm{Ser}^{220}$ ), and $\mathrm{Ser}^{226}$ (mouse $\mathrm{Ser}^{234}$ ) and are associated with GR activity [37, 38]. Here, we tested the hypothesis that the co-chaperone Fkbp5 regulates phosphorylation of GR in $F k b p 5^{\mathrm{PVN}-1-}$ and $F k b p 5^{\mathrm{PVN} \mathrm{OE}}$ mouse lines. To do so, we dissected the PVN of $F k b p 5^{\mathrm{PVN}-/-}$ and
Fkbp5 $5^{\mathrm{PVN} O \mathrm{OE}}$ mice and measured the phosphorylation levels of $\mathrm{Ser}^{203}, \mathrm{Ser}^{211}$, and $\mathrm{Ser}^{234}$ under basal and stress conditions.

Under basal conditions, animals lacking Fkbp5 in the PVN showed significantly less GR phosphorylation at $\mathrm{Ser}^{203}$ (Fig. 4A). Furthermore, Fkbp $5^{\mathrm{PVN}-1-}$ animals displayed higher phosphorylation of GR at $\operatorname{Ser}^{234}$ and $\operatorname{Ser}^{211}$ in comparison to their WT littermates (Fig. 4B, C). Under stressed conditions, deletion of Fkbp5 had the same effects on $\mathrm{pGR}^{\mathrm{Ser} 211}$ and $\mathrm{pGR}^{\mathrm{Ser} 234}$ as we observed under basal conditions (Fig. 4B, C). Levels of $\mathrm{pGR}^{\mathrm{Ser} 203}$ were found to be unchanged in the $F k b p 5^{\mathrm{PVN}-I_{-}}$after acute stress compared to the basal levels. However, $\mathrm{pGR}^{\mathrm{Ser} 203}$ levels of the control group increased after stress (Fig. 4A).

Intriguingly, $F k b p 5^{\mathrm{PVN} O E}$ animals showed exactly the opposing phenotype at all three phosphorylation sites with less $\mathrm{pGr}^{\mathrm{Ser} 234}$ and $\mathrm{pGr}^{\mathrm{Ser} 211}$ and higher phosphorylation at $\mathrm{Ser}^{203}$ under basal conditions (Fig. $4 \mathrm{E}-\mathrm{G}$ ). In parallel to the unstressed condition, the overexpression of Fkbp5 resulted in less GR phosphorylation at $\mathrm{Ser}^{211}$ and higher levels of $\mathrm{pGR}^{\mathrm{Ser} 203}$ compared to their control group after stress (Fig. 4E, F). Interestingly, levels of $\mathrm{pGR}^{\mathrm{Ser} 234}$ were unchanged after stress (Fig. 4G). Notably, total GR levels were not significantly altered in both experimental groups and conditions (Fig. 4D, H). Despite the altered GR phosphorylation, we could not detect any significant changes in 
A

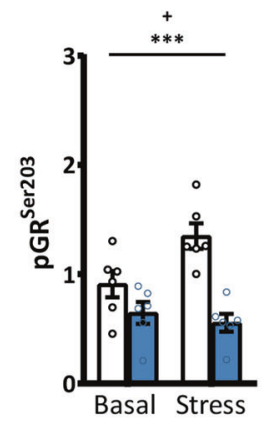

E

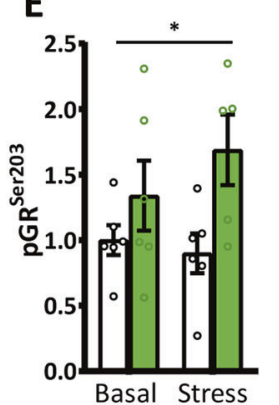

B

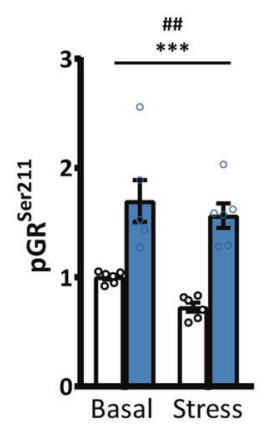

$\mathbf{F}$

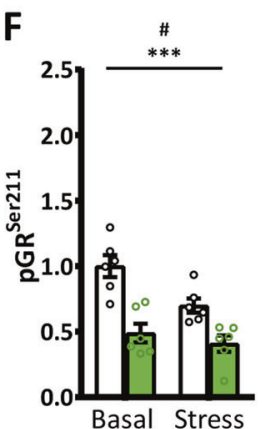

C

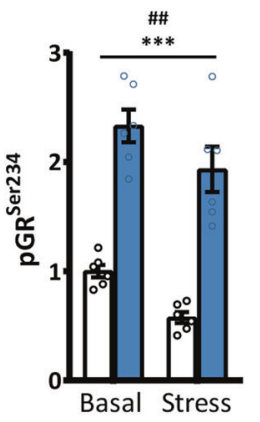

G

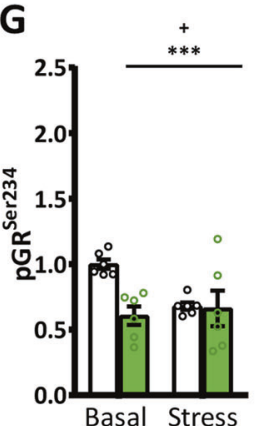

D

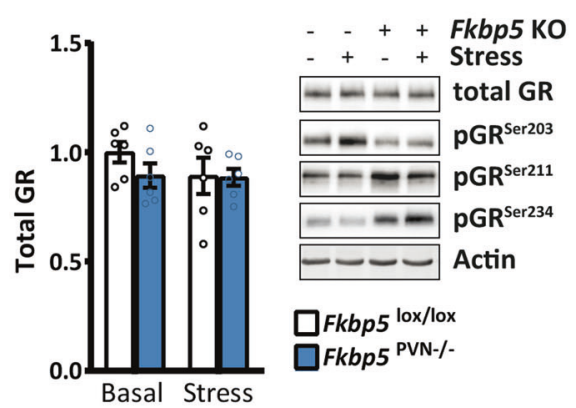

H

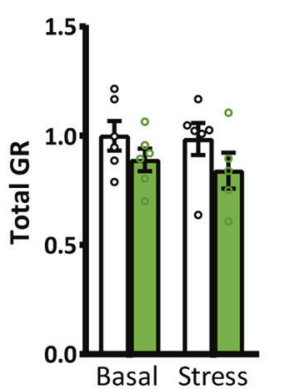

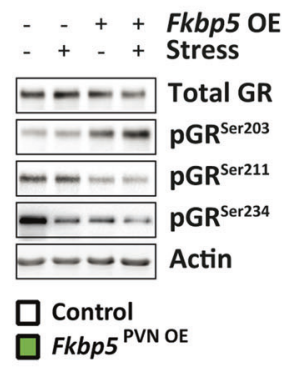

Fig. 4 Fkbp5 manipulation affects phosphorylation of the glucocorticoid receptor (GR). A Animals lacking Fkbp5 in the PVN showed significantly lower phosphorylation at $\mathrm{pGR}^{\mathrm{Ser} 203}$ and higher levels of (B) $\mathrm{pGR}^{\mathrm{Ser} 211}$ and $(\mathbf{C}) \mathrm{pGR}^{\mathrm{Ser} 234}$ compared to the control animals. D Fkbp5 $5^{\mathrm{PVN}-l-}$ mice showed no differences in total GR. E Fkbp5 ${ }^{\mathrm{PVN} O E}$ animals showed the opposite effect on GR phosphorylation with higher phosphorylation on $\mathrm{pGr}^{\mathrm{Ser} 203}$. F In addition, we observed significantly lower phosphorylation at the GR sites $\mathrm{Ser}^{211}$

GR enrichment at the glucocorticoid response element (GRE) in the Crh gene after acute stress (Supplementary Fig. 6), which may be due to the use of an antibody that recognizes all GR molecules irrespective of its phosphorylation state.

Overall, our data demonstrate that Fkbp5 manipulation in the PVN affects GR phosphorylation at all three major phosphorylation sites and thereby affects GR activity.

\section{Fkbp5 in the PVN acts in a complex cellular context}

To further unravel the expression profile of Fkbp5 in the PVN and to detect cellular populations that might be mediating the effects of Fkbp5 on HPA axis control, we used a single-cell RNA sequencing dataset consisting of 5113 single cells isolated from the PVN of $\mathrm{C} 57 \mathrm{Bl} / 6$ male mice [39]. The single-cell expression data reveal a complex cellular composition, with the majority of cells identified as neurons (38\%), ependymal cells (25\%), and astrocytes (14\%) (Fig. 5A-C). Fkbp5 was found to be differentially and cell-type specifically expressed, with the biggest $\mathrm{Fkbp5}^{+}$cell population found in GABAergic neurons (42\%). A significant expression of Fkbp5 was also detected and (G) $\operatorname{Ser}^{234}$. H Fkbp5 overexpression had no effect on total GR protein level. Representative blots are shown in $(\mathbf{D})$ and $(\mathbf{H})$. Group size for $(\mathbf{A})-(\mathbf{H})$ : 6 vs. 6 . Data were received from animals between 16 and 20 weeks of age and are presented as relative fold change to control condition, mean \pm SEM, and were analyzed with a two-way ANOVA. *significant genotype effect, $\left({ }^{*} p<0.05, * * p<0.01, * * * p<\right.$ $0.001)$. + significant genotype $\times$ stress interaction $\left({ }^{+} p<0.05\right)$, ${ }^{\#}$ significant stress effect $\left({ }^{\#} p<0.05,{ }^{\#} p<0.01\right)$.

in neuronal populations known to be directly involved in HPA axis regulation, most prominently in $\mathrm{Crh}$ positive neurons (Fig. 5D). However, it is important to point out that the expression levels of $F k b p 5$ are relatively low. Unfortunately, lowly expressed genes may not be detected using this technique [40] and therefore many Fkbp5 positive cells may have remained undetected in this dataset. To circumvent this problem, we next performed a targeted coexpression study of $F k b p 5$ with five major markers that are characteristic of the stress response oxytocin $(O x t)$, somatostatin $(S s t)$, vasopressin $(A v p)$, thyrotropin-releasing hormone (Trh), and $\mathrm{Crh}$ under basal and stress conditions (Fig. 5E, Supplementary Fig. 7). We observed a strong but not complete co-localization of Fkbp5 expression with these neuropeptide-expressing cellular populations in the PVN under basal conditions. Interestingly, a detailed quantification of the change in co-expression following stress revealed that there was a significant increase in Crh-Fkbp5 co-localization only in the Crh-expressing neurons (Fig. 5E, F and Supplementary Fig. 8).

These data reveal the complex cell-type-specific expression pattern of Fkbp5 under stress and basal conditions in the PVN. The significant increase of FKBP51 in 
A Overview single-cell sequencing
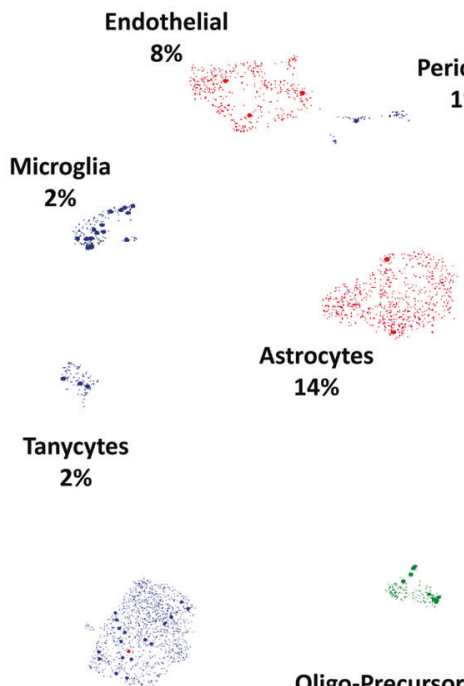

Ependymal $25 \%$

E Fkbp5 mRNA in Crh+ neurons

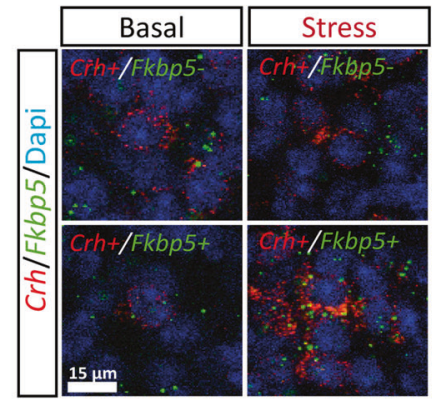

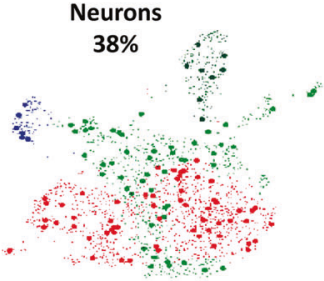

Oligo-Precursor $3 \%$

Oigodendrocytes $7 \%$
B Total Fkbp5+ cell population

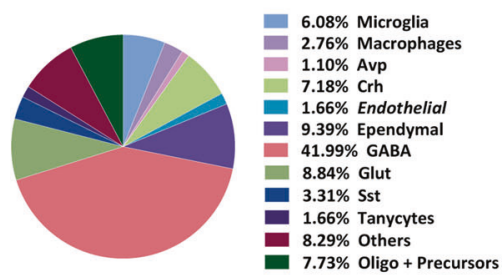

C Main neuronal supopulations

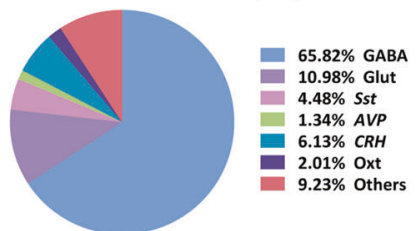

D Neuronal Fkbp5 distribution

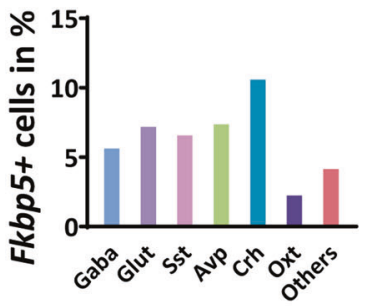

F Stress stimulated upregulation of Fkbp5+ mRNA

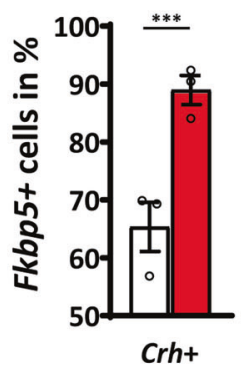

Fig. 5 Single-cell RNA sequencing of cells in the PVN of C57Bl/6 male mice under non-stressed conditions. A Single-cell sequencing depicted several different cell types. With the majority being neurons (38\%), ependymal cells (25\%), and astrocytes (14\%). Fkbp $5^{+}$cells are highlighted. B Diversity of $F k b p 5^{+}$cell population. C Neurons could be divided mostly into GABAergic (66\%) and glutamatergic (Glut, $11 \%$ ) cells. Furthermore, the well-known stress markers corticotropinreleasing hormone $(\mathrm{Crh}, 6 \%)$, somatostatin $(\mathrm{Sst}, 5 \%)$, oxytocin $(\mathrm{Oxt}$,
$2 \%)$, and vasopressin (Avp, 1\%) could be detected under basal conditions. D Fkbp5 ${ }^{+}$cells of selected neuronal subpopulations under basal conditions. E RNAscope validation of Fkbp 5 mRNA expression in $\mathrm{Crh}+$ neurons. F Quantity of $\mathrm{Fkbp5}^{+}$cells, as well as Fkbp5 mRNA levels, are significantly increased after stress. Data are were received from animals between 8 and 12 weeks of age and are presented as mean \pm SEM. For $(\mathbf{E})$ : data were analyzed with student's $t$ test. $* * * p<0.001$.
Crh positive neurons after an acute stress challenge encouraged us to specifically manipulated FKBP51 in Crh positive neurons.

\section{Crh-specific overexpression of Fkbp5 in the PVN alters HPA axis physiology and CRH neuronal activity}

Based on the observed increase in Crh-Fkbp5 colocalization post-stress (Fig. 5E, F and Supplementary
Fig. 8), we were interested whether a Crh-specific Fkbp5 overexpression in the PVN could drive the stress-like phenotype observed in the unspecific PVN overexpression (Fig. 2) and whether this neuron-specific manipulation alters CRH neuronal activity. Therefore, we bilaterally injected $200 \mathrm{nl}$ of an AAV containing a Cre-dependent Fkpb5 overexpression vector into the PVN of adult (26 weeks) CRH-ires-CRE/Ai9 mice expressing tdTomato specifically in $\mathrm{CRH}$ neurons ( $F k b p 5^{\mathrm{CRH} O \mathrm{OE}}$ ) (Fig. 6A). Credependent AAV mediated overexpression resulted in a 
A Experimental procedure
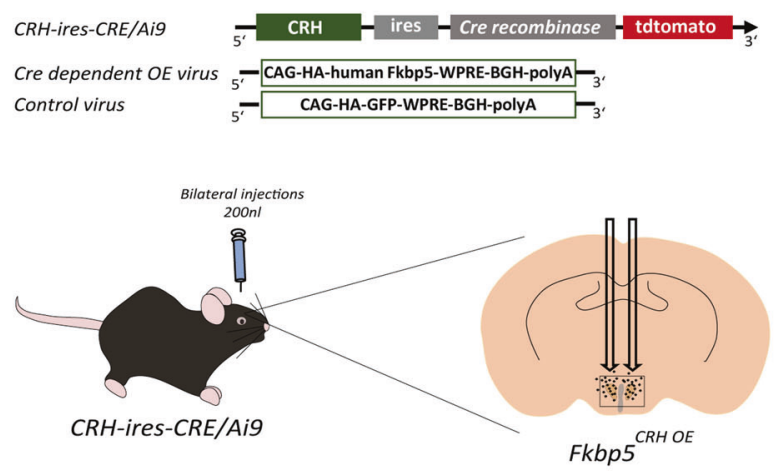

B Virus validation
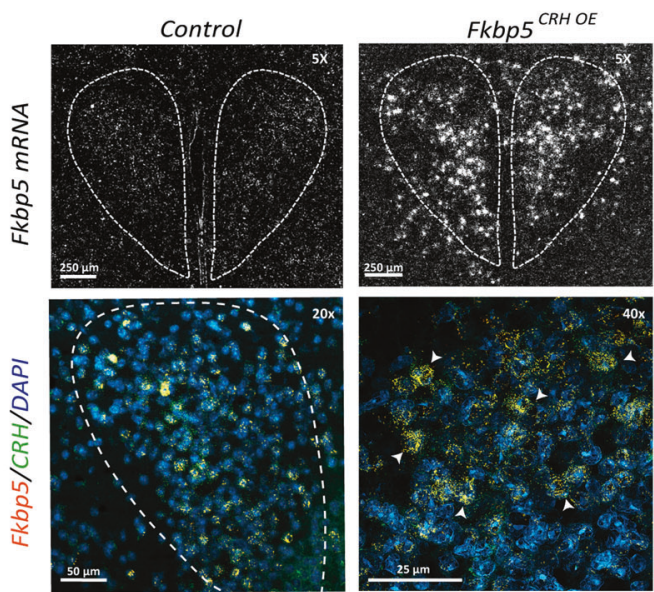

\section{Body physiology}

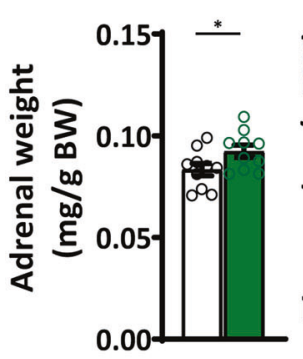

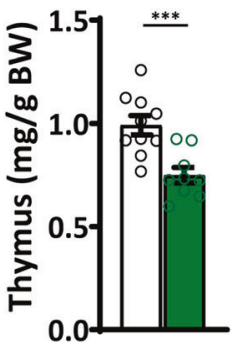

D Acute stress response

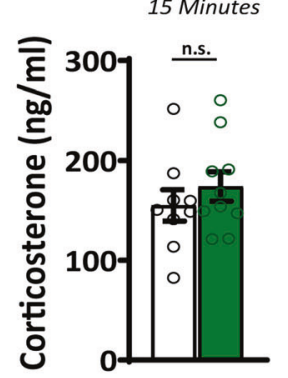

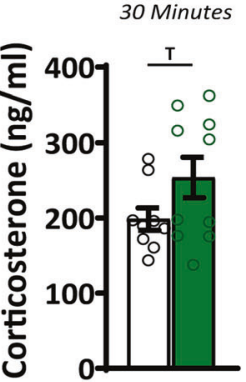

60 Minutes

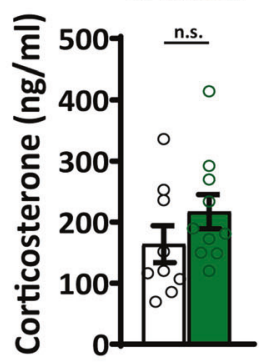

E Electrophysiology

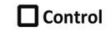

$\square$ Fkbp5 $^{\mathrm{CRH} O E}$
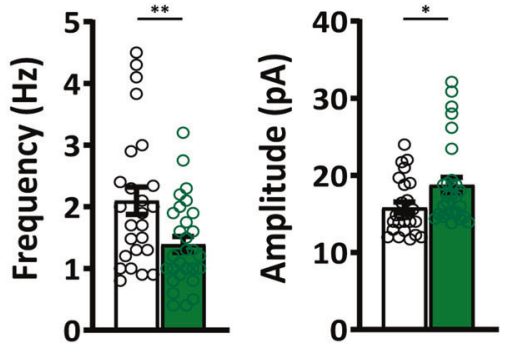

Control

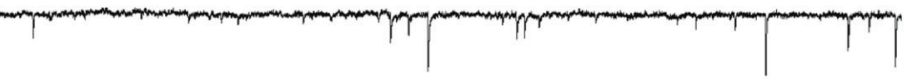

Fkbp5 $5^{\text {CRH OE }}$

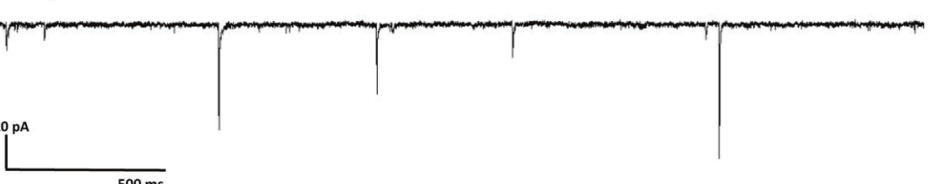

Fig. 6 The $C r h$-specific overexpression of Fkbp5 in the PVN. A $C r h$-specific overexpression of $F k b p 5$ in the PVN was achieved by bilateral injections of a Cre-dependent Fkbp5 overexpression virus in the PVN of CRH-ires-CRE/Ai9 mice. B Validation of $\mathrm{Crh}$-specific Fkbp5 mRNA overexpression in the PVN by ISH and RNAscope. Arrowheads pointing at viral Fkbp5 expressing $\mathrm{Crh}^{+}$neurons (For mRNA quantification see Supplementary Fig. 9D). C Fkbp5 $5^{\mathrm{CRH}} \mathrm{OE}$ mice showed significantly increased adrenal weights $(n=10)$ and reduced thymus weights $(n=9)$ under non-stressed conditions compared to the controls $(n=10)$. D Corticosterone levels were mildly,

fourfold increase of Fkbp5 mRNA level in the PVN and $\mathrm{Crh}$ specificity of $\mathrm{Fkbp} 5$ overexpression was successfully confirmed by RNAscope (Fig. 6B and Supplementary Fig. 9E). Under basal conditions, $F k b p 5^{\mathrm{CRH}} \mathrm{OE}$ mice displayed significantly increased adrenal weights and reduced thymus weights compared to the control group (Fig. 6C), but not significantly increased in $F k b p 5^{\mathrm{CRH} \mathrm{OE}}$ at 15,30 , and $60 \mathrm{~min}$ post-stress $\left(F k b p 5^{\mathrm{CRH} \mathrm{OE}} n=10\right.$; Control $\left.n=9\right)$ ). E $F k b p 5^{\mathrm{CRH} \mathrm{OE}}$ mice displayed a decrease in CRH neuronal mEPSC frequency accompanied by an increased amplitude $\left(F k b p 5^{\mathrm{CRH} \mathrm{OE}} n_{\text {mouse }}=4 ; n_{\text {neuron }}=\right.$ 29; Control $n_{\text {mouse }}=4 ; n_{\text {neuron }}=25$ ), which is reflected in two representative recording traces. Data are presented as mean \pm SEM. All data were received from animals between 30 and 34 weeks of age and analyzed with the student's $t$-test. $* p<0.05, * * p<0.01$, ***p $<<0.001$, $T=0.05<p<0.1$, n.s. not significant.

indicative of chronic hyperactivity of the HPA axis. Surprisingly, the circadian rhythm of corticosterone secretion (Supplementary Fig. 9A), as well as stress-induced corticosterone level (Fig. 6D), were unaffected by the Crhspecific Fkbp5 overexpression. Further, basal and 15 min post-stress ACTH level and DEX/CRH corticosterone level 
remained unaffected in $F k b p 5^{\mathrm{CRH} O \mathrm{OE}}$ mice (Supplementary Fig. 9B-D). To further assess the impact of Fkbp5 overexpression on neuronal activity in $\mathrm{Crh}$ positive $\left(\mathrm{Crh}^{+}\right)$ neurons in the PVN, we recorded AMPA receptor-mediated mEPSCs in these cells using cell patch-clamp recordings in a separate cohort. Fkbp 5 overexpression decreased the frequency of mEPSC frequency while increasing amplitude (Fig. 6E). This data shows that the Fkbp5 expression level in $\mathrm{Crh}^{+}$neurons can steer CRH neuronal activity within the PVN, whereas the baseline- and stress phenotype of $F k b p 5^{\mathrm{CRHOE}}$ mice is mostly unaffected by the manipulation, identifying $\mathrm{Crh}^{+}$neurons as one important but not the only driver of the observed stress-like $F k b p 5^{\mathrm{PVN} O E}$ phenotype.

\section{Discussion}

FKBP5 was first associated with stress-related disorders in 2004 [13] and has been studied extensively over the past 15 years with regard to stress regulation and sensitivity. However, detailed cell-type and region-specific manipulations of Fkbp5 in the brain are still lacking. In this study, we highlight the importance of this co-chaperone in the regulation of the acute stress response through the combined analysis of deletion, overexpression, and rescue of Fkbp5 exclusively in the PVN.

Fkbp5 is a stress-responsive gene and past research has shown that its main effects occur after chronic or acute stress [8, 18, 28, 32, 41]. Given that deletion of Fkbp5 in the PVN mimics the previously described phenotype of Fkbp5 KO mice $[28,41]$, with regard to their basal neuroendocrine profile and HPA axis function, our data illustrate that the functional contribution of Fkbp5 to HPA axis activity is centered in the PVN. In addition, reinstatement of native basal Fkbp 5 expression in the PVN of Fkbp $5 \mathrm{KO}$ mice was sufficient to normalize HPA axis function. Interestingly, the phenotype of intensified HPA axis suppression due to the loss of Fkbp5 in the PVN emerges only in adult animals, excluding developmental effects and underlining the previously reported importance of Fkbp5 in aging [42, 43].

Further, our results highlight the essential role of Fkbp5 in stress adaptation, as PVN-specific Fkbp5 excess is sufficient to reproduce all physiological and endocrinological hallmarks of a chronic stress situation [29, 44]. Interestingly, the results of our $F k b p 5^{\mathrm{PVN} \mathrm{OE}}$ cohort are comparable to the neuroendocrine effect of GR deletion in the PVN [45] and are in line with the high PVN-specific FKBP5 expression in rats with a hyperactive HPA axis [20]. The consequence of a heightened Fkbp5 expression in the PVN is twofold. Firstly, it leads to direct changes in GR sensitivity and downstream GR signaling directly in the PVN. Secondly, PVN Fkbp5 overexpression dramatically affects GR sensitivity and feedback at the level of the pituitary, as demonstrated by the inability of a low Dex dose (that does not cross the blood-brain barrier and acts predominantly at the level of the pituitary [26]) to suppress corticosterone secretion. This secondary effect is likely due to the constant overproduction of CRH in the PVN and very similar to the effects of HPA hyperactivity observed in many depressed patients $[33,46]$.

Mechanistically, we explored the role of Fkbp5 in modulating GR phosphorylation. The status of GR phosphorylation at $\operatorname{Ser}^{211}, \mathrm{Ser}^{203}$, and $\operatorname{Ser}^{234}$ is associated with transcriptional activity, nuclear localization, and ability to associate with GRE containing promoters [37]. Whereas higher levels of phosphorylation at $\operatorname{Ser}^{211}$ are associated with full transcriptional activity and localization in the nucleus, increased phosphorylation of $\operatorname{Ser}^{203}$ is linked to a transcriptionally inactive form of GR within the cytoplasm and thereby less active GR [38, 47, 48]. In our experiments, overexpression of Fkbp5 resulted in dephosphorylation at $\mathrm{Ser}^{211}$ and higher phosphorylation at $\mathrm{Ser}^{203}$, suggesting that the GR is mostly located in the cytoplasm and less active. Deletion of Fkbp5 showed the opposing effect, indicating a more active GR in $F k b p 5^{\mathrm{PVN}-1-}$ animals. Unfortunately, we were not able to analyze the GR phosphorylation in our $F k b p 5^{\text {PVN Rescue }}$ animals due to technical and breeding issues and therefore can only speculate that FKBP5 ${ }^{\text {PVN Rescue }}$ animals might have elevated levels of pGRSer203 and decreased levels of pGRSer211 and pGRSer234. It has previously been reported that GR phosphorylation is regulated by several kinases, including CDK5 and ERK [37, 49], and Fkbp5 has also been shown to be associated with CDK5 in the brain [50]. Therefore, we hypothesize that Fkbp5 also interacts with CDK5 to phosphorylate GR at multiple phosphorylation sites, thereby directly affecting ligand-dependent GR activity.

Given the complexity of the different cell types with highly specialized functions in the brain, it is essential to gain a deeper understanding of the cellular architecture of the PVN and the specific function of Fkbp5 in this context. Previously, it was assumed that Fkbp5 is quite widely expressed in most cell types of the nervous system [51]. However, our current data suggest that while Fkbp5 is indeed expressed in the PVN, it is enriched in specific subpopulations, including for example GABAergic neurons, $\mathrm{Crh}^{+}$neurons, and microglia, but largely absent in others, such as astrocytes and endothelial cells. Interestingly, when quantifying Fkbp5 regulation, we identified a highly selective regulation of $\mathrm{Fkbp5}$ in $\mathrm{Crh}^{+}$neurons, further supporting the central role of Fkbp5-controlled GR feedback in this neuronal subpopulation.

To further disentangle the role of Fkbp5 within Crh positive neurons in the acute stress response and HPA-axis feedback regulation, we selectively overexpressed $F k b p 5$ in $\mathrm{Crh}^{+}$cells within the PVN and assessed baseline- and 
stress-induced phenotypes paralleled by selective patchclamp recordings from $\mathrm{Crh}^{+}$neurons. Fkbp5 overexpression enhanced the amplitude of mEPSCs in $\mathrm{Crh}^{+}$ cells indicating a postsynaptic and, thus, the direct effect of our Fkbp5 manipulation on excitatory neurotransmission onto these neurons. This effect, which was accompanied by a diminished rate of mEPSC, potentially arises from accelerated recycling of internalized AMPA receptors to the postsynaptic density [52] and suggests an increased activity of $\mathrm{Crh}^{+}$-cells. However, Fkbp5 overexpression only partially recapitulating the HPA-axis phenotype observed in the $F k b p 5^{\mathrm{PVN}}$ OE mice. The unselective Fkbp5 overexpression in $F k b p 5^{\mathrm{PVN} O E}$ animals targeted a broad range of Fkbp5 expressing cell populations within the PVN, amongst which are oxytocin and vasopressin. Their essential contribution to the initiation and termination of the HPA-axis is well established, with vasopressin (together with $\mathrm{CRH}$ ) inducing ACTH release from the pituitary [53] and oxytocin enhancing the negative feedback helping to dampen the stress response [54]. Hence, our data suggest that Fkbp5 might play an essential role in at least one further neuronal subpopulation of the PVN driving the observed stress-like phenotype of $F k b p 5^{\mathrm{PVN}}$ OE mice in concert with CRH neurons.

The current study also comes with a number of limitations. Importantly, only male animals were used and the conclusions should therefore only be drawn with respect to male HPA axis regulation. Furthermore, given the fact that we did not observe differences in ACTH levels after stress, we cannot exclude that Fkbp5 manipulations in the PVN also drive changes in adrenal sensitivity, e.g., via alterations of sympathetic adrenal innervation [55]. Furthermore, the time course of $\mathrm{CRH}$ and ACTH release is quite different from the CORT response, so our measures may have missed a differential regulation. In fact, a modest increase in circulating ACTH at certain times of the circadian rhythm can indeed lead to adrenal hypertrophy and increased sensitivity, thereby contributing to increased CORT secretion even following comparable ACTH levels. Finally, the lack of ACTH data in the Dex/CRH test was technically unavoidable but also limits the conclusions with regard to the involved mechanism.

In summary, this study is the first to specifically manipulate Fkbp5 in the PVN and underlines its central importance in shaping HPA axis regulation and the acute stress response. The results have far-reaching implications for our understanding of stress physiology and stress-related disorders.

Acknowledgements The authors thank Claudia Kühne, Mira Jakovcevski, Daniela Harbich, and Bianca Schmid (Max Planck Institute of Psychiatry, Munich, Germany) for their excellent technical assistant and support. We thank Stefanie Unkmeir, Sabrina Bauer, and the scientific core unit Genetically Engineered Mouse Models for genotyping support. Further, we want to thank Alina Tontsch and the core unit BioPRep (Biomaterial Processing and Repository) for ELISA analysis of ACTH samples. This work was supported by the "OptiMD" grant of the Federal Ministry of Education and Research (01EE1401D; MVS), the BioM M4 award "PROCERA" of the Bavarian State Ministry (MVS), the "Kids2Health" grant of the Federal Ministry of Education and Research (01GL1743C; MVS) and by a NARSAD Young Investigator Grant from the Brain and Behavior Research Foundation (JH).

Author contributions ASH, and MVS: conceived the project and designed the experiments. JMD: provided scientific expertize for establishing Fkbp5 mouse lines. ASH and LMB managed the mouse lines and genotyping. ASH, MLP, LR, and LMB performed animal experiments and surgeries. RS: performed CORT and ACTH hormone assays and analysis. J-PL, SR, and EB: performed single-cell sequencing experiments and analysis. JMHMR, and HMG: Performed and analyzed GR-CHIP experiments. ASH, JH, LMB, and CE: performed and designed RNAscope experiments and manual counting of cells. NCG, TB, and KH: Performed protein analysis. ME and DM: designed, performed, and analyzed single-cell patch-clamp experiments. KJR and AC: supervised and revised the manuscript. ASH: wrote the initial version of the manuscript. MVS: Supervised the research and all authors revised the manuscript.

Funding Open Access funding enabled and organized by Projekt DEAL.

\section{Compliance with ethical standards}

Conflict of interest The authors declare no competing interests.

Publisher's note Springer Nature remains neutral with regard to jurisdictional claims in published maps and institutional affiliations.

Open Access This article is licensed under a Creative Commons Attribution 4.0 International License, which permits use, sharing, adaptation, distribution and reproduction in any medium or format, as long as you give appropriate credit to the original author(s) and the source, provide a link to the Creative Commons license, and indicate if changes were made. The images or other third party material in this article are included in the article's Creative Commons license, unless indicated otherwise in a credit line to the material. If material is not included in the article's Creative Commons license and your intended use is not permitted by statutory regulation or exceeds the permitted use, you will need to obtain permission directly from the copyright holder. To view a copy of this license, visit http://creativecommons. org/licenses/by/4.0/.

\section{References}

1. De Kloet ER, Joëls M, Holsboer F. Stress and the brain: from adaptation to disease. Nat Rev Neurosci. 2005;6:463-75.

2. Sinars CR, Cheung-Flynn J, Rimerman RA, Scammell JG, Smith DF, Clardy J. Structure of the large FK506-binding protein FKBP51, an Hsp90-binding protein and a component of steroid receptor complexes. Proc Natl Acad Sci USA. 2003;100:868-73.

3. Wochnik GM, Rüegg J, Abel GA, Schmidt U, Holsboer F, Rein T. FK506-binding proteins 51 and 52 differentially regulate dynein interaction and nuclear translocation of the glucocorticoid receptor in mammalian cells. J Biol Chem. 2005;280:4609-16.

4. Scammell JG, Denny WB, Valentine DL, Smiths DF. Overexpression of the FK506-binding immunophilin FKBP51 is the 
common cause of glucocorticoid resistance in three new world primates. Gen Comp Endocrinol. 2001;124:152-65.

5. Binder EB, Bradley RG, Liu W, Epstein MP, Deveau TC, Mercer KB. et al. Association of FKBP5 polymorphisms and childhood abuse with risk of posttraumatic stress disorder symptoms in adults. JAMA. 2008;299:1291-305.

6. Denny WB, Valentine DL, Reynolds PD, Smith DF, Scammell JG. Squirrel monkey immunophilin FKBP51 is a potent inhibitor of glucocorticoid receptor binding. Endocrinology. 2000;141: 4107-13.

7. Ising M, Depping AM, Siebertz A, Lucae S, Unschuld PG, Kloiber S, et al. Polymorphisms in the FKBP5 gene region modulate recovery from psychosocial stress in healthy controls. Eur J Neurosci. 2008;28:389-98.

8. Touma C, Gassen NC, Herrmann L, Cheung-Flynn J, Bll DR, Ionescu IA. et al. FK506 binding protein 5 shapes stress responsiveness: modulation of neuroendocrine reactivity and coping behavior. Biol Psychiatry. 2011;70:928-36.

9. Westberry JM, Sadosky PW, Hubler TR, Gross KL, Scammell JG. Glucocorticoid resistance in squirrel monkeys results from a combination of a transcriptionally incompetent glucocorticoid receptor and overexpression of the glucocorticoid receptor cochaperone FKBP51. J Steroid Biochem Mol Biol. 2006;100:34-41.

10. Scharf SH, Liebl C, Binder EB, Schmidt MV, Müller MB. Expression and regulation of the Fkbp5 gene in the adult mouse brain. PLoS ONE. 2011;6:1-10.

11. Zannas AS, Binder EB. Gene-environment interactions at the FKBP5 locus: sensitive periods, mechanisms and pleiotropism. Genes Brain Behav. 2014;13:25-37.

12. Matosin N, Halldorsdottir $\mathrm{T}$, Binder EB. Understanding the molecular mechanisms underpinning gene by environment interactions in psychiatric disorders: the FKBP5 model. 2018. https:// doi.org/10.1016/j.biopsych.2018.01.021.

13. Binder EB, Salyakina D, Lichtner P, Wochnik GM, Ising M, Pütz $\mathrm{B}$, et al. Polymorphisms in FKBP5 are associated with increased recurrence of depressive episodes and rapid response to antidepressant treatment. Nat Genet. 2004;36:1319-25.

14. Klengel T, Mehta D, Anacker C, Rex-Haffner M, Pruessner JC, Pariante CM, et al. Allele-specific FKBP5 DNA demethylation mediates gene-childhood trauma interactions. Nat Neurosci. 2013;16:33-41.

15. Young KA, Thompson PM, Cruz DA, Williamson DE, Selemon LD. BA11 FKBP5 expression levels correlate with dendritic spine density in postmortem PTSD and controls. Neurobiol Stress. 2015;2:67-72.

16. Sinclair D, Fillman SG, Webster MJ, Weickert CS. Dysregulation of glucocorticoid receptor co-factors FKBP5, BAG1 and PTGES3 in prefrontal cortex in psychotic illness. Sci Rep. 2013;3:1-10.

17. Gassen NC, Hartmann J, Zschocke J, Stepan J, Hafner K, Zellner A, et al. Association of FKBP51 with priming of autophagy pathways and mediation of antidepressant treatment response: evidence in cells, mice, and humans. PLoS Med. 2014;11: e1001755.

18. Hartmann J, Wagner KV, Gaali S, Kirschner A, Kozany C, Ruhter $\mathrm{G}$, et al. Pharmacological inhibition of the psychiatric risk factor FKBP51 has anxiolytic properties. J Neurosci. 2015;35:9007-16.

19. Herman JP, McKlveen JM, Ghosal S, Kopp B, Wulsin A, Makinson R, et al. Regulation of the hypothalamic-pituitaryadrenocortical stress response. Compr Physiol. 2016;6:603-21.

20. Walker SE, Zanoletti O, Guillot de Suduiraut I, Sandi C. Constitutive differences in glucocorticoid responsiveness to stress are related to variation in aggression and anxiety-related behaviors. Psychoneuroendocrinology. 2017. https://doi.org/10.1016/j. psyneuen.2017.06.011.
21. Rodríguez CI, Buchholz F, Galloway J, Sequerra R, Kasper J, Ayala R, et al. High-efficiency deleter mice show that FLPe is an alternative to Cre- loxP. Nat Genet. 2000;25:139-40.

22. Balthasar N, Dalgaard LT, Lee CE, Yu J, Funahashi H, Williams $\mathrm{T}$, et al. Divergence of melanocortin pathways in the control of food intake and energy expenditure. Cell. 2005;123:493-505.

23. Dedic N, Kühne C, Jakovcevski M, Hartmann J, Genewsky AJ, Gomes KS, et al. Chronic CRH depletion from GABAergic, longrange projection neurons in the extended amygdala reduces dopamine release and increases anxiety. Nat Neurosci. 2018;21:803-7.

24. Schmidt MV, Schulke J-P, Liebl C, Stiess M, Avrabos C, Bock J, et al. Tumor suppressor down-regulated in renal cell carcinoma 1 (DRR1) is a stress-induced actin bundling factor that modulates synaptic efficacy and cognition. Proc Natl Acad Sci USA. 2011;108:17213-8.

25. Paré WP, Glavin GB. Restraint stress in biomedical research: a review. Neurosci Biobehav Rev. 1986;10:339-70.

26. Karssen AM, Meijer OC, Berry A, Sanjuan Piñol R, De Kloet ER. Low doses of dexamethasone can produce a hypocorticosteroid state in the brain. Endocrinology. 2005;146:5587-95.

27. Jakovcevski M, Schachner M, Morellini F. Susceptibility to the long-term anxiogenic effects of an acute stressor is mediated by the activation of the glucocorticoid receptors. Neuropharmacology. 2011;61:1297-305.

28. Hartmann J, Wagner KV, Liebl C, Scharf SH, Wang XD, Wolf M, et al. The involvement of FK506-binding protein 51 (FKBP5) in the behavioral and neuroendocrine effects of chronic social defeat stress. Neuropharmacology. 2012;62:332-9.

29. Schmidt MV, Sterlemann V, Ganea K, Liebl C, Alam S, Harbich D, et al. Persistent neuroendocrine and behavioral effects of a novel, etiologically relevant mouse paradigm for chronic social stress during adolescence. Psychoneuroendocrinology. 2007;32:417-29.

30. Alexander Wolf F. PA and FJT. SCANPY: large-scale single cell data analysis. Genome Biol. 2017;19:2926-34.

31. Johnson WE, Li C, Rabinovic A. Adjusting batch effects in microarray expression data using empirical Bayes methods. Biostatistics. 2007;8:118-27.

32. Mifsud KR, Reul JMHM. Acute stress enhances heterodimerization and binding of corticosteroid receptors at glucocorticoid target genes in the hippocampus. Proc Natl Acad Sci USA. 2016;113:11336-41.

33. Ising M, Holsboer F. Genetics of stress response and stress-related disorders. Dialogues Clin Neurosci. 2006;8:433-44.

34. Wagner KV, Marinescu D, Hartmann J, Wang XD, Labermaier C, Scharf $\mathrm{SH}$, et al. Differences in FKBP51 regulation following chronic social defeat stress correlate with individual stress sensitivity: influence of paroxetine treatment. Neuropsychopharmacology. 2012;37:2797-808.

35. Nestler EJ, Barrot M, DiLeone RJ, Eisch AJ, Gold SJ, Monteggia LM. Neurobiology of depression. Neuron. 2002;34:13-25.

36. Tsigos C, Chrousos GP. Hypothalamic-pituitary-adrenal axis, neuroendocrine factors and stress. J Psychosom Res. 2002;53:865-71.

37. Galliher-Beckley AJ, Cidlowski JA. Emerging roles of glucocorticoid receptor phosphorylation in modulating glucocorticoid hormone action in health and disease. IUBMB Life. 2009;61:979-86.

38. Wang Z, Frederick J, Garabedian MJ. Deciphering the phosphorylation 'code' of the glucocorticoid receptor in vivo. J Biol Chem. 2002;277:26573-80.

39. Dournes C, Dine J, Lopez J-P, Brivio E, Anderzhanova E, Roeh S, et al. Hypothalamic glucocorticoid receptor in CRF neurons is essential for HPA axis habituation to repeated stressor. BioRxiv. 2020:2020.11.30.402024.

40. Luecken MD, Theis FJ. Current best practices in single-cell RNAseq analysis: a tutorial. Mol Syst Biol. 2019;15:e8746. 
41. Hoeijmakers L, Harbich D, Schmid B, Lucassen PJ, Wagner KV, Schmidt MV, et al. Depletion of FKBP51 in female mice shapes HPA axis activity. PLoS ONE. 2014. https://doi.org/10.1371/ journal.pone.0095796.

42. Sabbagh JJ, O'Leary JC, Blair LJ, Klengel T, Nordhues BA, Fontaine SN, et al. Age-associated epigenetic upregulation of the FKBP5 gene selectively impairs stress resiliency. PLoS ONE. 2014;9:e107241.

43. O'Leary JC, Dharia S, Blair LJ, Brady S, Johnson AG, Peters M, et al. A new anti-depressive strategy for the elderly: ablation of FKBP5/FKBP51. PLoS ONE. 2011;6:e24840.

44. Klein F, Lemaire V, Sandi C, Vitiello S, Van der Logt J, Laurent PE. et al. Prolonged increase of corticosterone secretion by chronic social stress does not necessarily impair immune functions. Life Sci. 1992;50:723-31.

45. Laryea G, Arnett M, Muglia LJ. Ontogeny of hypothalamic glucocorticoid receptor-mediated inhibition of the hypothalamicpituitary-adrenal axis in mice. Stress. 2015. https://doi.org/10. 3109/10253890.2015.1046832.

46. De Kloet ER. Hormones and the stressed brain. Ann N Y Acad Sci. 2004;1018:1-15.

47. Blind RD, Garabedian MJ. Differential recruitment of glucocorticoid receptor phospho-isoforms to glucocorticoid-induced genes. J Steroid Biochem Mol Biol. 2008;109:150-7.

48. Krstic MD, Rogatsky I, Yamamoto KR, Garabedian MJ. Mitogenactivated and cyclin-dependent protein kinases selectively and differentially modulate transcriptional enhancement by the glucocorticoid receptor. Mol Cell Biol. 1997;17:3947-54.
49. Kino T, Ichijo T, Amin ND, Kesavapany S, Wang Y, Kim N, et al. Cyclin-dependent kinase 5 differentially regulates the transcriptional activity of the glucocorticoid receptor through phosphorylation: clinical implications for the nervous system response to glucocorticoids and stress. Mol Endocrinol. 2007;21:1552-68.

50. Gassen NC, Hartmann J, Zannas AS, Kretzschmar A, Zschocke J, Maccarrone G, et al. FKBP51 inhibits GSK3 $\beta$ and augments the effects of distinct psychotropic medications. Mol Psychiatry. 2016;21:277-89.

51. Scharf SH, Schmidt MV. Animal models of stress vulnerability and resilience in translational research. Curr Psychiatry Rep. 2012;14:159-65.

52. Blair LJ, Criado-Marrero $M$, Zheng D, Wang X, Kamath S, Nordhues BA, et al. The disease-associated chaperone FKBP51 impairs cognitive function by accelerating AMPA receptor recycling. ENeuro. 2019;6:ENEURO.0242-18.

53. Sapolsky RM, Romero LM, Munck AU. How do glucocorticoids influence stress responses? Integrating permissive, suppressive, stimulatory, and preparative actions. Endocr Rev. 2000;21:55-89.

54. Winter J, Jurek B. The interplay between oxytocin and the CRF system: regulation of the stress response. Cell Tissue Res. 2019.

55. Leon-Mercado L, Chao DHM, Basualdo M del C, Kawata M, Escobar C, et al. The arcuate nucleus: a site of fast negative feedback for corticosterone secretion in male rats. ENeuro. 2017. https://doi.org/10.1523/ENEURO.0350-16.2017. 